\title{
Chapter 2 \\ Social and Life History Strategies of Tibetan Macaques at Mt. Huangshan
}

\author{
Jin-Hua Li and Peter M. Kappeler
}

\subsection{Introduction}

Among the more than 25 species of Macaca, the Tibetan macaque (Macaca thibetana) is relatively late to be known in primatology. There are several reasons for this. First, it had been considered as a subspecies of Macaca speciosa until Fooden (1983), based on his re-examination of the form and size of the glans penis and baculum and the structure of the female reproductive tract, elevated it to species status. Second, Tibetan macaques are endemic to east central China, where most of them inhabit high mountains with dense forests and cliff ledges, making field studies very challenging. Third, as argued above (Sun et al. 2019), there were few Chinese researchers interested in studying primates until the 1980s. As a result, the population status, life history, and social organization of $M$. thibetana have remained relatively poorly known.

Existing information, though still limited, indicates that the Tibetan macaque may be special in many ways. Morphologically, it resembles the stump-tailed macaque, M. arctoides (Delson 1980). Phylogenetically, it is close to the Assamese macaque, M. assamensis, as indicated by both morphological (Delson 1980) and genetic

\footnotetext{
J.-H. Li ( $\square)$

School of Resources and Environmental Engineering, Anhui University, Hefei, Anhui, China International Collaborative Research Center for Huangshan Biodiversity and Tibetan Macaque Behavioral Ecology, Anhui, China

School of Life Sciences, Hefei Normal University, Hefei, Anhui, China

e-mail: jhli@ahu.edu.cn

P. M. Kappeler

Behavioral Ecology and Sociobiology Unit, German Primate Center, Leibniz Institute for Primate Research, Göttingen, Germany

Department of Anthropology/Sociobiology, University of Göttingen, Göttingen, Germany e-mail: pkappel@gwdg.de
} 
analyses (Hoelzer et al. 1992). Ecologically and behaviorally, it is more similar to the Barbary macaque, M. sylvanus, because both live in montane habitats near the subtropical/temperate boundary, have a similar diet, and share intensive infant care with "bridging behavior," which involves two adults simultaneously lifting up an infant (Ogawa 2019). Yet, the four abovementioned species have been placed into different species groups within the genus Macaca by Fooden (1980) and Delson (1980), leading Wada et al. (1987) to suggest that the Tibetan macaque is a key species for understanding the evolution of Asian Macaca. These are the main reasons why $M$. thibetana has attracted much interest among primatologists lately.

Tibetan macaques have been listed as a Class II protected species in China since 1988, and they were classified as "Near Threatened" by the IUCN Red List of Threatened Species in 2017. Four subspecies of Tibetan macaque (M. t. thibetana, M. t. guizhonensis, M. t. huangshanensis, and M. t. pullus) have been identified based on morphological comparisons (Jiang et al. 1996) and mtDNA analyses (Sun et al. 2010). These subspecies represent distinct conservation units (Liu et al. 2006). Since M. t. huangshanensis is the most genetically distinctive and geographically isolated taxon (Sun et al. 2010), it deserves particular attention ( $\mathrm{Li}$ et al. 2008) (Fig. 2.1).

\subsection{Long-term Study of Tibetan Macaques at Mt. Huangshan}

The Mt. Huangshan study site is located in southern Anhui province in East China (118.3E, $30.2 \mathrm{~N}$, elevation $1841 \mathrm{~m}$ ), about $1000 \mathrm{~km}$ south of Beijing. It covers an area of $154 \mathrm{~km}^{2}$ with a south-north dimension of $40 \mathrm{~km}$ and an east-west extension of $30 \mathrm{~km}$. This region is primarily made up of granite with many separate, sharp peaks and cliffs, which prevent people from gaining access to most parts. The weather in the mountain changes with altitude, from subtropical near the bottom, to temperate on the slopes, and to cold at the peak. Correspondingly, the vegetation changes from evergreen broad-leaved forest near the base, to deciduous and evergreen broad-leaved mixed forest on the slopes, and to montane grassland at the top. Mean temperature is $7.8^{\circ} \mathrm{C}$ with the highest mean temperature in August $\left(25.6{ }^{\circ} \mathrm{C}\right)$ and the lowest in January $\left(-19.8{ }^{\circ} \mathrm{C}\right)(\mathrm{Li} 1999)$. Mt. Huangshan is a well-known scenic spot and a popular tourist destination in China and is listed as a World Cultural and Natural Heritage Site, a World Geological Park, and is in the Man and the Biosphere Programme (MAB) (Fig. 2.2).

Two primate species inhabit these mountains: the Tibetan macaque and the rhesus macaque (M. mulatta). Tibetan macaques inhabit higher altitudes above $600 \mathrm{~m}$ asl with rocky cliffs, whereas the rhesus macaques live in lower areas with a relatively continuous distribution (Wada et al. 1987). Both have been strictly protected from hunting and trapping since the 1940s and have no known large predators.

Nine social groups of Tibetan macaques are currently living in Mt. Huangshan, where they maintain apparently nonoverlapping home ranges (Wada et al. 1987). 


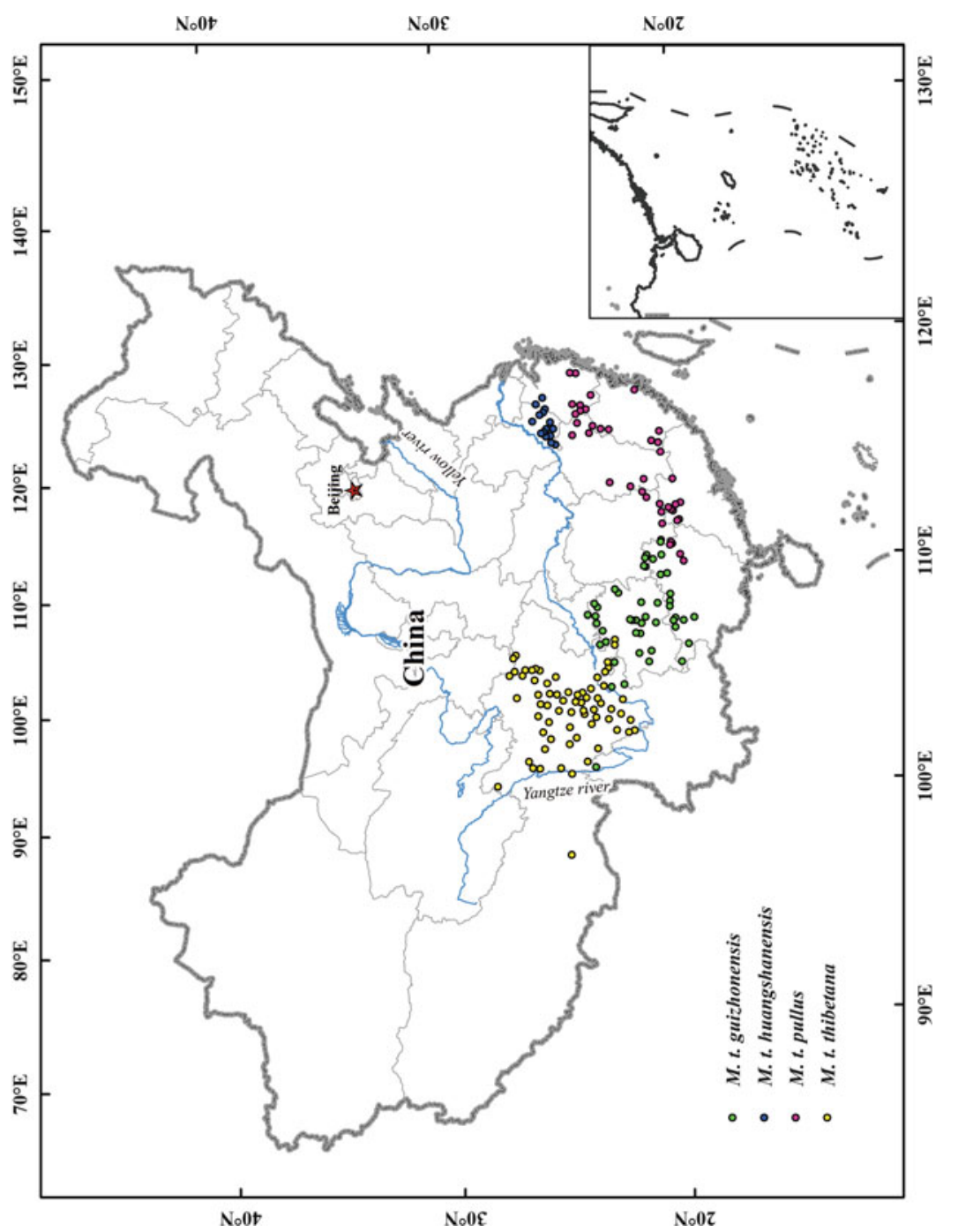



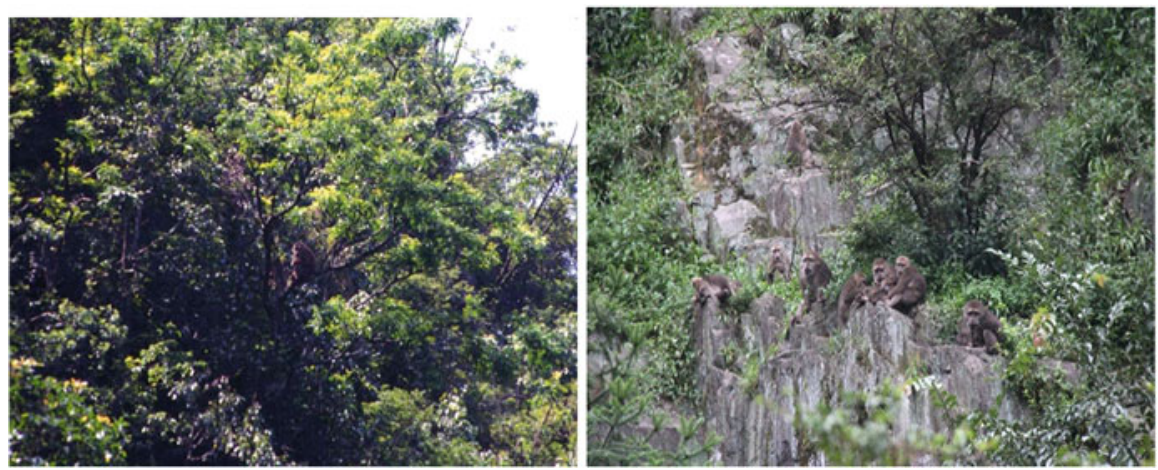

Fig. 2.2 Tibetan macaques inhabit high mountains with evergreen broad-leaved forest (left) and rocky cliffs (right)

They occur in two types of forest and mixed forest: the evergreen broad-forest between 500 and $1000 \mathrm{~m}$ asl and deciduous and evergreen mixed broad-forest between 800 and $1200 \mathrm{~m}$ asl. They are heavily reliant on structural plant parts for food with marked seasonality: bamboo and grass shoots in spring; fruits, nuts, acorns, and tubers in fall; and bark and mature leaves in winter, supplemented with invertebrates year-round (Xiong and Wang 1988). Geophagy has been observed in terms of ingesting yellow clay from well-established spots and licking rocks that are in contact with soil (Wang et al. 2007). In winter, Tibetan macaques huddle together and sleep on the terraces of rocky cliffs (Xiong 1984), but in summer, they spend the night in trees, which are cool and are safe from venomous snakes (Li and Wang 1994).

Our long-term study group is named Yulingken group (lately Yulingken A or YA1 following a recent group fission) at the village of Fuxi in the southern part of the mountain. The group has been monitored continuously since 1986. To facilitate observation, we have provisioned the group with dried maize to attract them to an open area by a stream. An amount of 5-6 kg of maize per day, which is about $1 / 3$ of the daily food intake of the group, has been given by local wardens 3-4 times a day on a set schedule. When not being fed, the macaques spend most of their time in the forest near the provisioning area. Provisioning has made it possible for us to study the group in a steep terrain and has prolonged our observational time, though it may inevitably affect their natural activities to some extent (Matheson et al. 2006).

We set up a standard study protocol for long-term collection of consistent data within and among researchers at the beginning of the study in 1986. Since then, we have recognized individuals from birth on (natal individuals) or first discovery (immigrated individuals) and given them Chinese names. We have identified each group member based on individually specific physical characteristics such as body size, fur color, facial features, and body scars and taken pictures for confirmation and comparison over time. Furthermore, since Tibetan macaques have broad faces and long fur, both of which change with age, we can fairly reliably sort them into age-sex groups: infant ( $<1$ year), juvenile ( $1-3$ years), adolescent ( $\precsim 3-7$ years, + $3-5$ years), 
young adult ( $\$ 7-10$ years, $\$ 5-10$ years), middle-aged adult ( $10-15$ years), and old adult ( $>15$ years). Our records show that a male can live up to 28 years (Gaoshan) and a female up to 33 years old (Hua). They both died of old age. Because all females in the group have been identified after their births, we have been able to trace matrilineal relationships among all group members since 1983. Recently, we used microsatellite DNA markers to determine paternity for most group members (Appendix I). For behavioral data collection, we have followed Altmann's methods (Altmann 1974) and recognized and defined 33 distinct social behaviors (Li 1999, see Appendix II). In order to conduct genetic, physiological, and microbiological analyses, we have developed noninvasive techniques to collect cell or hormone samples from the feces and saliva of living monkeys (Zhao et al. 2005; Simons et al. 2012).

The long-term study of Tibetan macaques at Mt. Huangshan has been ongoing for over 30 years. It is the longest research project for wild primates in China. More than 150 researchers and students from the United States, Japan, Australia, England, and Germany as well as China have visited or conducted research at our field site, and 50 theses and 12 dissertations have been completed. This project is now recognized among the eight sites in the world for the long-term study of free-living monkeys (Kappeler and Watts 2012). Recently, as an integral part of the International Research Center for Huangshan Biodiversity and Tibetan Macaque Behavioral Ecology, the project has been approved by the Anhui provincial government.

\subsection{Social Life History Strategies}

\subsubsection{The Largest Macaca}

It is difficult to study Tibetan macaques in the wild because of their elusiveness and aggression, so catching and weighing them is nearly impossible. An unexpected opportunity to obtain morphometric data presented itself in July 1988, however, when 17 individuals of our study group died within 10 days for a reason that is still unknown. We obtained morphometric data from 14 of the 17 corpses. The average weight for adult males, adult females, and neonates are $16.4(n=4), 11.0(n=3)$, and $0.60 \mathrm{~kg}(n=2)$, respectively. They were all heavier than members of the same age-sex classes in other Macaca species (Table 2.1). Apparently, the Tibetan macaque is the heaviest species in the genus Macaca. This may be the reason why local people call them "bear monkeys." This result has been verified by morphometric analysis of 72 linear dental and cranial variables of 11 macaque species, showing that the two stump-tailed species (M. thibetana and M. arctoides) are the largest of the macaques (Pan et al. 1998). 
Table 2.1 Body weights $(\mathrm{kg})$ of some Macaca species

\begin{tabular}{l|l|l|l}
\hline Species & Adult male & Adult female & Neonate \\
\hline M. thibetana & 16.4 & 11.0 & 0.60 \\
M. fuscatta & 11.7 & 9.1 & 0.50 \\
M. sylvanus & 11.2 & 10.0 & - \\
M. nemestrina & 10.4 & 7.8 & 0.47 \\
M. nigra & 10.4 & 6.6 & 0.49 \\
M. maura & 9.5 & 5.1 & - \\
M. arctoides & 9.2 & 8.0 & 0.49 \\
M. silenus & 6.8 & 5.0 & - \\
M. radiata & 6.6 & 3.7 & 0.40 \\
M. sinica & 6.5 & 3.4 & - \\
M. mulatta & 6.2 & 3.0 & 0.48 \\
M. fascicularis & 5.9 & 4.1 & 0.35
\end{tabular}

Note: the data for species other than M. thibetana are from Smuts et al. (1987)

\subsubsection{Medium-Sized Group with Even Adult Sex Ratios}

We monitored the size and composition of Yulingken group annually and found a fluctuation of 21-51 individuals with an average of 35.3 individuals $(S E=1.6$ ) over the 30 years from 1987 to 2017 . Whenever group size reached about 50 individuals, it fissioned into two subgroups and the smaller one of the two subgroups left the study area. During this period, we recorded four fission events happening in 1993, 1996, 2001, and 2003, respectively (Li et al. 1996; Li 1999; Berman and Li 2002), and noticed that males and females who were relatives tended to separate on these occasions (Li et al. 1996). Thus, Tibetan macaques at Mt. Huangshan appear to live in medium-sized groups, in comparison with the 70-80 and sometimes more than 100 individuals found in groups of other macaque species (Macintosh et al. 2012; Waters et al. 2015). Group size is an important component of social organization that determines how many individuals a group member can potentially interact with, which in turn contributes to social complexity (Kappeler and Watts 2012).

Like other species of Macaca, Tibetan macaques are organized into multi-male, multi-female groups with female philopatry and male dispersal (Li et al. 1996; Li and Wang 1996). However, male Tibetan macaques do not leave their natal groups until adulthood, later than most Macaca in which male transfers typically occur at puberty (Zhao 1993; Li et al. 1996). Thus, Tibetan macaque groups tend to include large proportions of natal adult males and relatively even sex ratios $(0.91 \pm 0.05)$, with an average of $8.52(S E=0.67)$ adult males to $9.35(S E=0.51)$ adult females (Fig. 2.3).

\subsubsection{A Rich Repertoire of Affiliative and Ritualized Behaviors}

An important feature of Tibetan macaques is their rich repertoire of affiliative and ritualized behaviors. Of the 33 social behaviors we have identified, at least 


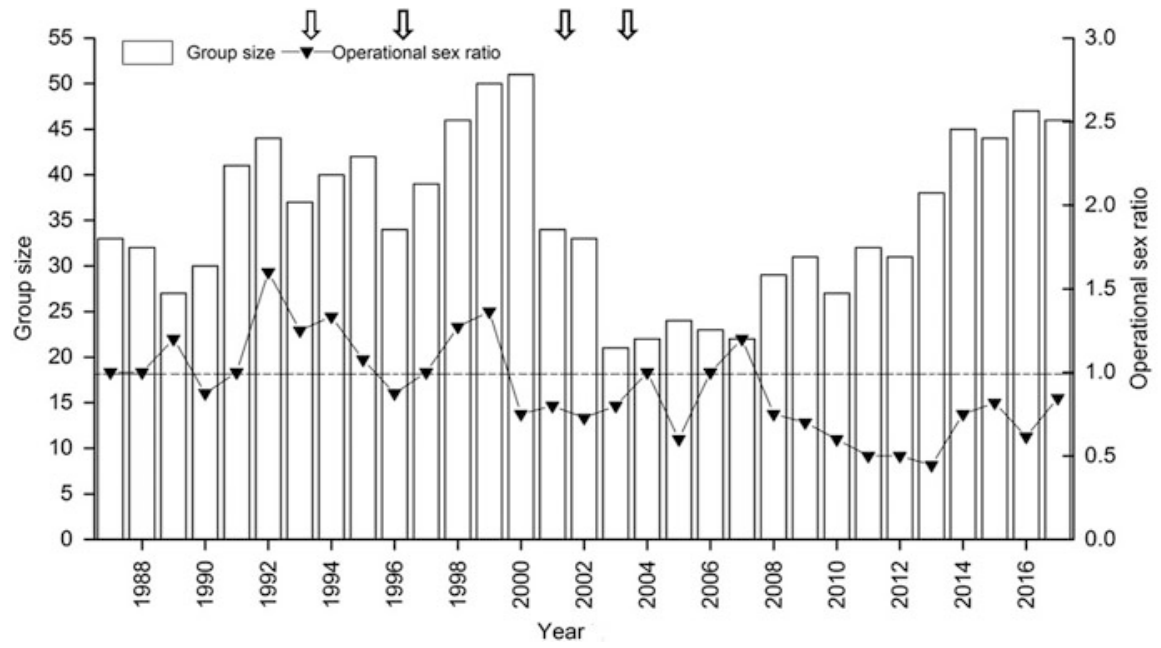

Fig. 2.3 Dynamic of group size and operational sex ratio of male to female in Yulingken A1 group during 1986 and 2017. Down arrow refers group fission events

17 (> 50\%) include affiliation (Li 1999). Like other macaques, allogrooming (social grooming) is widespread among all group members and takes up about $20 \%$ of daily time expenditure (Wang et al. 2007). Females and juveniles are more active groomers than males in peaceful situations. Grooming is more frequent between sexual partners than between other male-female pairs. Specifically, higher-ranking males, including alpha males, groom females for a short time after copulation or during consortship. Grooming between adult males is also frequent (Xia et al. 2013). When two individuals meet, the lower-ranking individual usually presents to the high-ranging individual. If the two individuals are both males, they may embrace each other, sometimes with their hands stretching out to grasp the genitals of their partners. Additionally, the lower-ranking individual may approach a higher-ranking one, showing its penis to be sucked by the partner, or the higher-ranking individual touches a part of the body (head, back, or shoulder) of the lower-ranking individual or mounts the lower-ranking individual with teeth chattering. If the two individuals are of the opposite sex, the male may grimace at the female, and the female approaches the male for genital inspection, before copulation ensues. Also, during conflicts between two females, a third, higher-ranging female may often approach and hold the bottom of the attacking female to stop further aggression.

Tibetan macaques show an intense interest in infants. Group members, regardless of sex or age, often hold infants. Sometimes, an individual picks up an infant and carries it to another individual to perform the ritualized behavior of bridging. This behavior can occur between males, between females, and between a male and a female (Ogawa 1995a; Li 1999). The infants used in bridging are predominantly younger than 6 months, but occasionally 2-3-year-old juveniles may also be used 

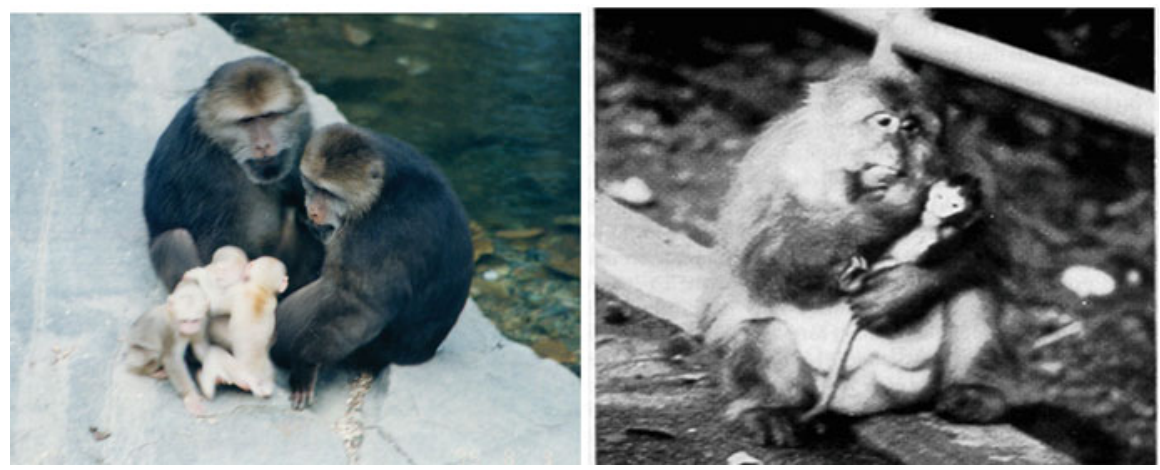

Fig. 2.4 Infant-holding behavior in Tibetan macaques is common. Left: three infants are attracted to two adult males, apparently waiting to be held or used in bridging. Right: a male Tibetan macaque living alone in Kowloon in Hong Kong holds an infant long-tailed macaque

(Zhang et al. 2018). Infants appear to be willing for bridging and mothers appear to be tolerant of infant handling by all group members (Fig. 2.4).

\subsubsection{Despotic Dominance Style}

The dominance style concept has proven useful for understanding covariation patterns in relationship qualities, particularly among macaques (Berman et al. 2004). As a member of the sinica lineage, Tibetan macaques are predicted to have a relaxed dominance style (Matsumura 1999; Thierry 2000). Previous studies did indicate relaxed dominance in this species. For example, males frequently engage in ritualized greetings in which they groom, mount, embrace, or touch each other's genitalia (Li 1999). In addition, both sexes engage in frequent bridging, and infants' mothers appear to be tolerant of infant handling by a wide range of group members (Ogawa 1995a).

However, a detailed study indicated that Tibetan macaques are more despotic than previously suspected. Bidirectional aggression, including counter-aggression (1.9\%) and conciliatory tendency (6.4\%), was consistently low in frequency across partner combinations, seasons, and locations (Berman et al. 2006). Females consistently displayed high levels of kin bias in affiliation and tolerance. Compared to other macaque species with better known dominance styles, data from Tibetan macaques generally fall within the range characteristic of despotic species and outside the range of relaxed species (Berman et al. 2004).

Despotic dominance of Tibetan macaques is consistent with our field observations. First, mating of low-ranking males was inhibited by high-ranking males. If a low-ranking male surreptitiously mated with a female in the forest but happened to be seen by a high-ranking male, the high-ranking male would immediately rush to punish him by scratching and biting. Second, when a series of conflicts happened, 

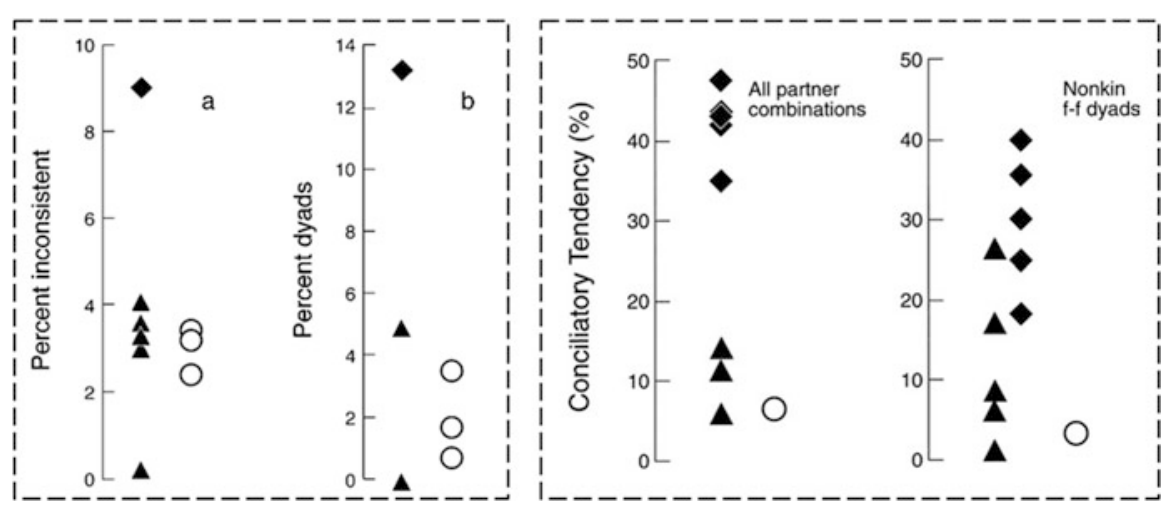

Fig. 2.5 Bidirectionality of aggression (left) and conciliatory tendencies of Tibetan macaques (right). Both a directional inconsistency index (a) and dyads-up index (percentage of dyads in which the primary direction of aggression is up the hierarchy of three data points representing three study periods for Tibetan macaques (circles)) fall within the range of despotic macaques (rhesus, longtailed and Japanese macaques) (triangles) and are considerably lower than the one relatively relaxed species (stump-tailed macaques) (diamonds). Conciliatory tendencies of Tibetan macaque in (1) all partner combinations and degrees of relatedness combined, and (2) unrelated female-female partners (circles) are relatively low, even compared to values for despotic macaques (triangles). Data from Berman et al. (2004)

male Tibetan macaques often formed a "power coalition," in which several highranking males support one another to defeat low-ranking ones (Li 1999). Third, serious fresh wounds on Tibetan macaques were frequently seen immediately after intense aggressive interactions (Fig. 2.5).

\subsubsection{Reproductive Pattern with Year-Round Mating but Seasonal Births}

It took a long time for us to understand the reproductive pattern of Tibetan macaques. At first, based on intermittent field observations, they were thought to be nonseasonal breeders (Wada and Xiong 1996). After intensive year-round observations, we found that, although mating indeed takes place throughout the year, mating with high frequency and with ejaculation occurs only between July and December, with subsequent births mostly occurring between January and April (Li 1999; Li et al. 2005). Thus, Tibetan macaques are seasonal breeders (Fig. 2.6).

In order to explain this unusual reproductive pattern of Tibetan macaques, we investigated changes in the female sexual skin and nonreproductive matings in more detail. We found that adult females had a slight but detectable sexual skin in the perineal region, but the sexual skin lacked the regular changes characteristic of the physiological cycle of a female or the reproductive season. Females also had no typical behaviors to show their sexual motivation during estrus. This led to the 


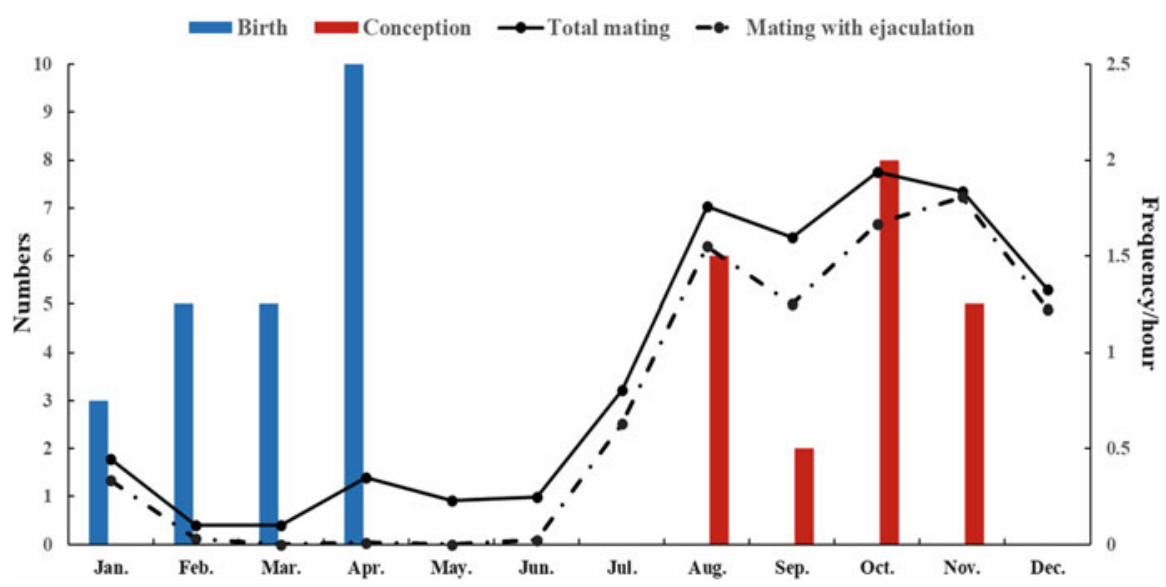

Fig. 2.6 Annual reproductive cycle of Tibetan macaques. Though Tibetan macaques mate yearround (solid line), mating with ejaculation (dotted line) is confined to a period from July to December. Therefore, the mating season is from July to December, and the birth season is from January to April

conclusion that Tibetan macaques have concealed ovulation (Li et al. 2005). Further study revealed that males could discriminate between potentially receptive females, but that they could not recognize the reproductive status of a given female (Li 1999; Zhang et al. 2010). Concealed ovulation may result in a higher mating frequency during a female's receptive period.

Compared with sexual behavior in the mating season, nonreproductive matings occurred at a lower frequency, with less frequent ejaculation, less harassment, shorter mount duration, and an absence of pauses with vocalization. It often took place in a situation in which non-lactating females were involved in social conflict or approached males for mating. Neither pregnant nor lactating females were observed to mate in the birth seasons. Copulation during the birth season did not affect a sexually receptive female's delivery the next year, nor was it associated with increased proximity, grooming, or agonistic aid within the mating pair. However, mating pairs spent more time co-feeding, presumably reflecting increased male tolerance ( $\mathrm{Li}$ et al. 2007). Adolescent males, who rarely copulated in the mating season, engaged in mating activities during birth seasons as well. Therefore, even though birth season copulations have no reproductive function, they might fulfill social functions for females, such as post-aggression appeasement by males or improving access to resources. They may also offer good opportunities for adolescent males and females to develop their sexual skills (Li et al. 2007) (Fig. 2.7).

It is worth noting that an important aspect of the mating pattern of Tibetan macaques at Mt. Huangshan is a single mount ejaculation (SME), with average duration and thrust numbers of $23.2 \mathrm{~s}$ and 20 times, respectively (Xiong and Wang 1991). High-ranking males copulate more often with more females than do low-ranking males, and alpha males monopolize over $2 / 3$ of all matings (Xiong 

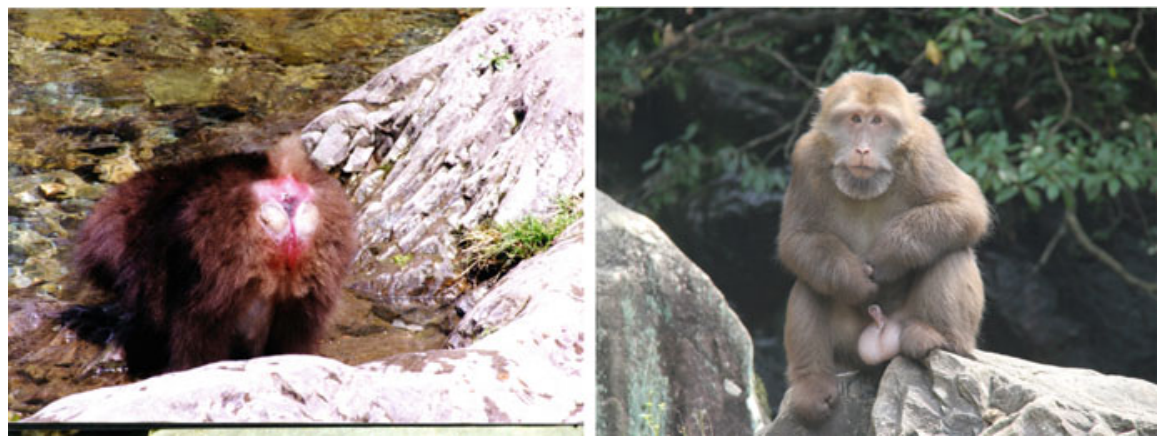

Fig. 2.7 Inconspicuous sexual skin in adult females (left) and large testes in adult males (right) in Tibetan macaque

and Wang 1991; Li et al. 2005). However, it has been reported that Tibetan macaques at Mt. Emei exhibit serial or multiple mount ejaculation with a mean duration and thrust number of mounts with $30.3 \mathrm{~s}$ and 43.3 times (MME), respectively (Zhao 1993). Since no data on the number of mounts in a MME have been provided, we do not know whether the difference is due to a difference in populations per se or observation methods.

Finally, females at the age of 7-12 years have the highest birth rate. Not only are birth rates of high-ranking females higher, but those of high-ranking females are also earlier than those of low-ranking ones in the birth season ( $\mathrm{Li}$ et al. 1994).

\subsection{Potential Contributions to Understanding Behavioral Mechanisms in Primate Societies}

\subsubsection{Bridge and Bond Role of Infant}

Tibetan macaques exhibit some interesting and unique behavior patterns. Bridging behavior is one of them. Bridging involves two individuals and an infant and is a triadic interaction. Bridging behavior is common in Tibetan macaque society, and it can be performed between males, between females, between a male and a female, and even between an adult and a juvenile. Infants of both sexes are involved in the "bridge." Despite this variation in bridging partners, bridging lasts only a few seconds. Once bridging has ended, the two bridging individuals often groom each other or sit together, ignoring the infant. Obviously, the "bridge" between monkeys is not for infant care, but for social contact or communication. In other words, infants are a "social tool" used to facilitate older group members' associations and interactions (Ogawa 1995b). Zhao (1996) even compared infants in bridging behavior to a cigarette-like social facilitator in human social interactions. 
Primatologists have always paid particular attention to the role of infants in nonhuman primate societies. However, most studies have focused on infant care or handling (Ogawa 1995a). For example, in capped langurs, Presbytis pileata, newborn infants of less than one month old spend nearly the same amount of time with alloparental females as with their own mothers (Stanford 1992). Likewise, young, female vervet monkeys, Chlorocebus aethiops sabaeus, without infants hold or carry newborn infants, which has been explained as alloparental investment (Fairbanks 1990). Bridging behavior has also been observed in M. sylvanus (Deag and Crook 1971). Clearly, infants in Tibetan and Barbary macaques play an active part in enhancing social relationships among group members. This is a relatively new and important research direction that is worthy of further exploration.

\subsubsection{Male-Female Friendships in a Promiscuous Mating System}

During the mating season from July to December, high-ranking Tibetan macaque males often follow sexually receptive females (usually those without unweaned infants). They move, feed, and rest together, often accompanied by mating; that is, they form a temporary consortship. The duration of such a consortship varies from a few days up to over 2 weeks (Li 1999). During a consortship, the male always keeps close with the female, and the male's activities are restricted by the female's movements. Sometimes, when a consorting male realizes that his female has disappeared, he shows signs of anxiety and searches for the female everywhere.

The role of consortship is unclear at present. On the one hand, the duration of consortship in Tibetan macaque is rather long, lasting as much as 18 continuous days (Li 1999). This does not only exceed the time needed to impregnate a female, but is also longer than the duration in other Macaca species (Li 1999). On the other hand, although a male follows one female at a time, usually he cannot monopolize all of her matings even though he is the alpha male. So why do high-ranking males use consortship as a mating tactic?

We already mentioned that female Tibetan macaques tend to conceal their ovulation by neither showing cyclical fluctuation of sexual skin nor estrus-related behaviors ( $\mathrm{Li}$ et al. 2005). Although high-ranking males form consortship with females, they are able to opportunistically mate with other sexually receptive females, too. Thus, the co-occurrence of consort behavior and opportunistic mating may indicate a male mating tactic that is effective when mating is promiscuous and males cannot accurately detect ovulation in females from morphological and behavioral signs. That is, consortship may be a tactic related to the assurance of paternity. From an evolutionary perspective, consortship in Tibetan macaques appears to be a special type of sexual relationship, which has also been reported for some baboons, where they have been labeled as "friendships" (Smuts 1985). 


\subsubsection{Competitive and Cooperative Relationships Among Males}

Male Tibetan macaques exhibit stable, linear dominance hierarchies typical of despotic species. On the one hand, aggression is frequent and can be accompanied by serious wounds in all sex/age classes (Berman et al. 2004; Li 1999). Additionally, the large body, large testes, and short tenures of alpha males (on average about 10 months) indicate intense competition among males ( $\mathrm{Li}$ and Wang 1996). On the other hand, Tibetan macaque males frequently engage in friendly behaviors, such as grooming and sitting together, and engage in ritualized greetings involving mounting, embracing, and sucking penis. Many of these behaviors are rarely seen in other Macaca males. Tibetan macaque males also quickly reconcile after aggression. The conciliatory tendency is $19.7 \%$ in male-male dyads, compared to $4.2 \%$ in femalefemale dyads, and most male-male reconciliations occur within 1 min after aggression (Berman et al. 2004). It is evident that male Tibetan macaques show both competitive and cooperative relationships. This appears to agree with observations taken from other primate societies with relatively male-biased adult sex ratios.

\subsubsection{Behavioral Mechanism Promoting Genetic Diversity in a Small Group}

Like most nonhuman primates in China, Tibetan macaques live in small, isolated populations. Theoretically, a small population or group may suffer the detrimental effects of inbreeding and the loss of genetic diversity (Spielman et al. 2004). Our study group is a medium-sized one with 20-50 individuals and that ranges in a small habitat ( $\mathrm{Li}$ et al. 1996). However, we have not found conspicuous changes in behavior during the 30-year period, except the sudden death of 17 individuals in the spring of 1988. Although we have noticed a decline in the frequency of affiliative interactions among group members and an increase in infant mortality in recent years, these appear to be a side effect of provisioning, which increases the rate of aggression among group members (Berman and Li 2002).

Additionally, we found that our study group has a relatively high haplotype diversity $(\mathrm{Hd}=0.341)$ when compared to other subspecies $(M$. t. pullus, $\mathrm{Hd}=0.222 ;$ M. $t$. guizhouensis, $\mathrm{Hd}=0.478$ ) (Sun et al. 2010). As such, loss of genetic diversity may not be a major concern in our study group at present. It is likely that some behavioral mechanisms in this group may play an important role in preventing or slowing down the loss of genetic diversity that is often observed in small groups. For instance, we found that the transfer of males into and out of the group occurs annually ( $\mathrm{Li}$ et al. 1996). Also, kin recognition may prevent mating between matrilineal relatives. In fact, one of our studies demonstrates that no copulation involved mother-son dyads, and only $2.1 \%(7 / 329)$ of copulations were 
between maternal siblings. Females may be more averse to copulating with relatives than are males (Zhu et al. 2008).

\subsection{Conclusions}

Long-term studies of primate populations are essential for documenting important events or phases of individual life histories that are critical for our understanding of subtle and complex relationships of group members that determine the nature and dynamic of social organization and, as a result, variation in individual reproductive success. The medium-sized group of Tibetan macaques we study facilitates censuses and unambiguous identification of all group members in the field. As the largest macaque species with a relatively male-biased adult sex ratio and year-round mating but seasonal birth, this species offers a large spectrum of sociodemographic conditions conducive for testing hypotheses related to dominance style and group fission. Furthermore, a rich repertoire of affiliative and ritualized behaviors and a complex interplay of competitive and cooperative relationships, especially among males, can provide primatologists with a wealth of opportunities to pursue additional behavioral, ecological, and evolutionary research projects focused on Tibetan macaques.

Acknowledgments Our long-term field study has been supported by Anhui University and the Huangshan Garden Bureau. Our research would be impossible without their assistance in terms of permission, personnel, funding, and other logistic support. For more than three decades, many researchers and students, especially those from Anhui University, Kyoto University, State University of New York at Buffalo, University of Washington, and Central Washington University, have joined and contributed to the study. We cordially thank Qi-Shan Wang, Kazuo Wada, Cheng-Pei Xiong, Guo-Qiang Quan, He-Ling Shen, Ren-Mei Ren, Ming Li, Jiao Shao, Zu-Wang Wang, Zhi-Gang Jiang, Kunio Watanabe, Hideshi Ogawa, Frans de Wall, Noel Rowe, Carol Berman, Consuel Ionica, Lei Zhang, Toshisada Nishida, Randall Kyes, Lisa Jones-Engel, Lixing Sun, Lori Sheeran, Megan Matheson, Steven Wagner, Dong-Po Xia, Bing-Hua Sun, Yong Zhu, Xi Wang, Yang Liu, Jian-Yuan Zhao, Jessica Mayhew, and Paul Garber for their full-hearted supports and noted contributions. We also express our thanks to Fu-Wen Wei, Bao-Guo Li, Yan-Jie Su, ChengMing Huang, Xue-Long Jiang, Ji-Qi Lu, and other members of China Primatology Society. This work was financially supported by the National Natural Science Foundation of China, the China Scholarship Council, the Key Teacher Program of the Ministry of Education of China, the Outstanding Youth Foundation of Anhui Province, the International Science and Technology Cooperation Plan of Anhui Province, Natural Science Foundation of Anhui Province, Inoue Scientific fund, Primate Conservation Inc., the L.S.B. Leakey Foundation, the Wenner-Gren Foundation, the ASP Conservation Small Grant, and the National Natural Science Foundation. Special thanks to Mr. Cheng's family and Fuxi villagers for their outstanding logistic support during our field observation for more than three decades. 


\section{Appendix I}

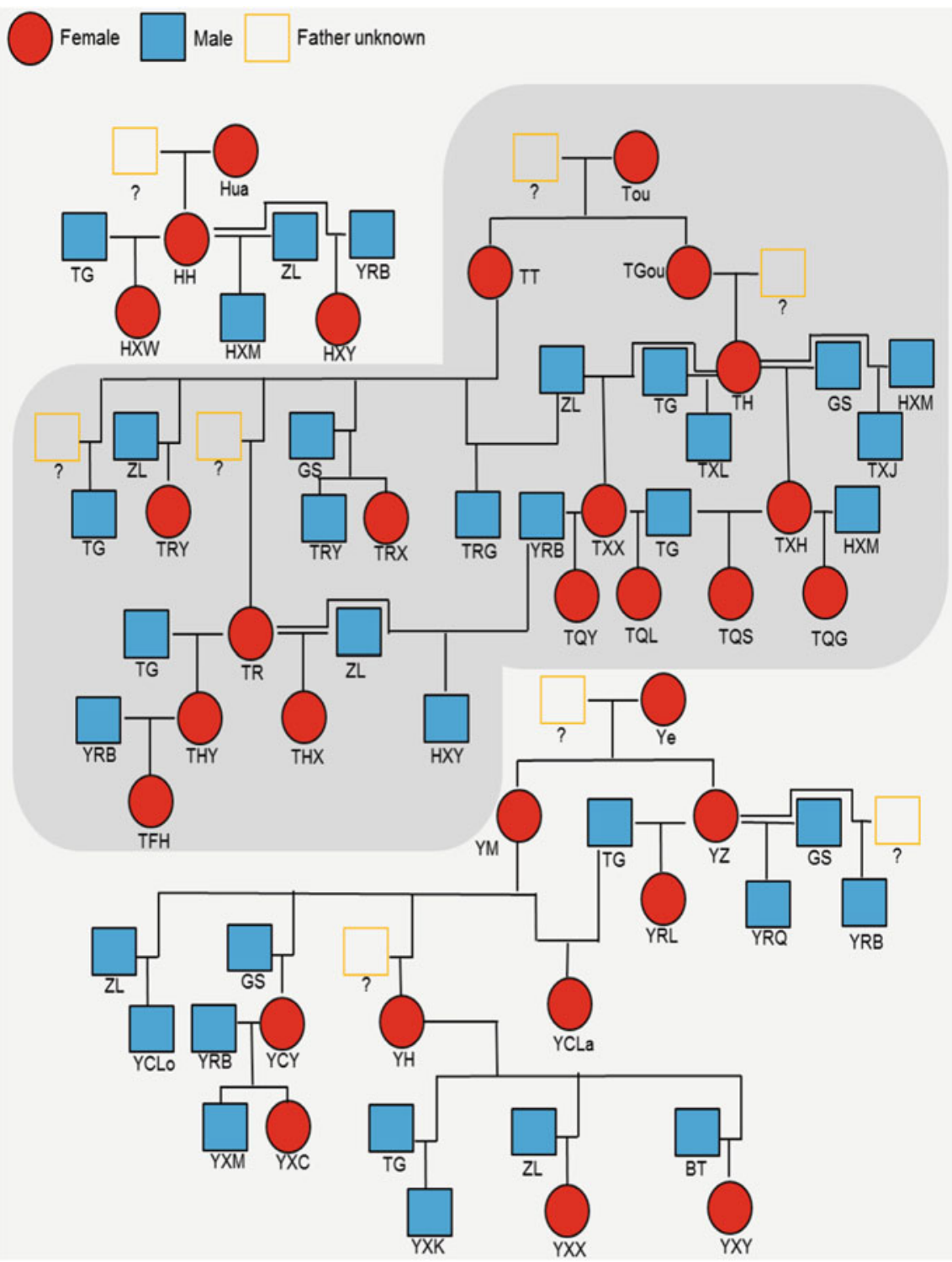

Pedigree of the YA1 social group of Tibetan macaques in Huangshan (September, 2017). Note: The pedigree was mapped based on maternal relationships of three matrilines. Males with known identities were also included. Letters under the blue squares (males) or red circles (females) represent individual names. Question marks indicate the identity of males are yet to be unknown 


\section{Appendix II}

Ethogram of social behaviors in Tibetan macaque

\begin{tabular}{|c|c|c|c|}
\hline No. & Repertoire & Definition & Picture \\
\hline 1 & Stare & $\begin{array}{l}\text { An individual looks directly at another individual with its } \\
\text { eyes wide open and with its shoulders raised for about } 3-5 \mathrm{~s} \text {. } \\
\text { The staring individual appears as if it is preparing to lunge or } \\
\text { chase the recipient of the stare. }\end{array}$ & Picture 1 \\
\hline 2 & Ground slap & $\begin{array}{l}\text { An individual places one hand on the ground and slaps the } \\
\text { ground, a rock, or some grassy vegetation with the other } \\
\text { while staring at the recipient. The ground slap may be } \\
\text { repeated several times. }\end{array}$ & Picture 2 \\
\hline 3 & Chase & $\begin{array}{l}\text { An individual stares at the recipient and rushes at him/her at } \\
\text { great speed. The recipient typically flees. }\end{array}$ & \\
\hline 4 & Seize & $\begin{array}{l}\text { The performer grabs the body, face, neck, or ear of the } \\
\text { recipient with one hand, shakes it, and then releases } \\
\text { it. Sometimes the performer also comes very close (face to } \\
\text { face) and stares at the recipient. }\end{array}$ & Picture 3 \\
\hline 5 & Bite & $\begin{array}{l}\text { The performer grabs the receiver tightly, preventing him/her } \\
\text { from fleeing, and bites the recipient vigorously. }\end{array}$ & Picture 4 \\
\hline 6 & Avoid & $\begin{array}{l}\text { The performer turns its body away from the attacker as if } \\
\text { preparing to flee while displaying a "horrified" facial } \\
\text { expression toward the attacker. }\end{array}$ & Picture 5 \\
\hline 7 & Flee & $\begin{array}{l}\text { The target of an attack will run in the opposite direction } \\
\text { from the attacker. }\end{array}$ & \\
\hline 8 & Scream & $\begin{array}{l}\text { A vocal reaction to an attacker. The scream is high pitched } \\
\text { and of long duration. This may be accompanied by fleeing. }\end{array}$ & Picture 6 \\
\hline 9 & Redirection & $\begin{array}{l}\text { When } \mathrm{A} \text { is attacked by } \mathrm{B}, \mathrm{A} \text { responds immediately by } \\
\text { attacking } \mathrm{C} \text {. } \mathrm{C} \text { is an individual that is nearby and lower- } \\
\text { ranking than both } \mathrm{A} \text { and } \mathrm{B} \text {. In some cases, B will join the } \\
\text { attack against C. }\end{array}$ & Picture 7 \\
\hline 10 & Solicit support & $\begin{array}{l}\text { When an individual is attacked by another individ- } \\
\text { ual, it intermittently scans the attacker and a higher-ranking } \\
\text { individual nearby with screams. The higher-ranking } \\
\text { bystander may respond by interrupting the attack on the } \\
\text { scanner. }\end{array}$ & Picture 8 \\
\hline 11 & Hold bottom & $\begin{array}{l}\text { The performer (usually the alpha female) approaches one of } \\
\text { two other females that are engaged in a fight. She } \\
\text { approaches from behind and holds the bottom of the female. } \\
\text { Both females typically teeth-chatter to one another. This } \\
\text { tends to interrupt the fight. }\end{array}$ & Picture 9 \\
\hline 12 & Approach & $\begin{array}{l}\text { An individual moves directly toward another individual, } \\
\text { coming within } 1 \mathrm{~m} \text {. }\end{array}$ & \\
\hline 13 & Leave & $\begin{array}{l}\text { An individual moves from within } 1 \mathrm{~m} \text { to more than } 1 \mathrm{~m} \text { of } \\
\text { another individual. }\end{array}$ & Picture 10 \\
\hline 14 & Proximity & $\begin{array}{l}\text { Two or more individuals are sitting or lying within } 1 \mathrm{~m} \text { or } \\
\text { between } 1 \text { and } 5 \mathrm{~m} \text { (depending on studies). }\end{array}$ & Picture 11 \\
\hline
\end{tabular}




\begin{tabular}{|c|c|c|c|}
\hline No. & Repertoire & Definition & Picture \\
\hline 15 & Following & $\begin{array}{l}\text { When one individual begins to travel from one location to } \\
\text { another, another individual nearby immediately goes in the } \\
\text { same direction. }\end{array}$ & Picture 12 \\
\hline 16 & Teeth chatter & $\begin{array}{l}\text { The performer opens his/her mouth, places the tongue close } \\
\text { to the teeth, and moves his/her jaw rapidly, thereby making } \\
\text { clicking noises with his/her teeth. The eyelids are lowered, } \\
\text { the chin is raised, and the tongue is moved rapidly back and } \\
\text { forth across the teeth. This behavior accompanies same-sex } \\
\text { mounting, embracing, and infant carrying. It appears to } \\
\text { function as a friendly invitation to interact. }\end{array}$ & Picture 13 \\
\hline 17 & Play & $\begin{array}{l}\text { Brief sequence of rapid, repetitive, and exaggerated move- } \\
\text { ments, without clear objectives. Interacting play movements } \\
\text { involving two or more individuals include chase, mock } \\
\text { fight, and combinations of previous behavior. }\end{array}$ & Picture 14 \\
\hline 18 & $\begin{array}{l}\text { Social } \\
\text { grooming/ } \\
\text { allogrooming }\end{array}$ & $\begin{array}{l}\text { One individual uses his/her fingers and palms to groom the } \\
\text { fur of another individual. The groomer may pick out small } \\
\text { objects from the recipients fur and eat them. }\end{array}$ & Picture 15 \\
\hline 19 & Embrace & $\begin{array}{l}\text { Two individuals, usually adult males, hold each other while } \\
\text { face to face. Each partner will reach with one hand and } \\
\text { attempt to touch the genitals of the other. Both partners } \\
\text { typically teeth-chatter and vocalize excitedly. }\end{array}$ & Picture 16 \\
\hline 20 & Touch & $\begin{array}{l}\text { A ritualistic behavior between males in which the lower- } \\
\text { ranking individual approaches the higher-ranking individual } \\
\text { in front. The higher-ranking male touches some part of the } \\
\text { body of the lower-ranking individual (head, back, shoulder). } \\
\text { Then the lower-ranking individual leaves. This may be used } \\
\text { in a tense situation and appears to be a means by which the } \\
\text { lower-ranking individual obtains "permission" to proceed } \\
\text { on its pathway or with its apparent goal. }\end{array}$ & \\
\hline 21 & Present & $\begin{array}{l}\text { One individual approaches the front of the other and shows } \\
\text { his bottom to the other. Usually the presenter is the lower- } \\
\text { ranking of the two partners. Females also present to males. }\end{array}$ & Picture 17 \\
\hline 22 & Mount & $\begin{array}{l}\text { One male (usually the lower-ranking) grabs the back hair of } \\
\text { another male and mounts from behind, using the full ankle } \\
\text { clasp posture. Both males teeth-chatter and scream excit- } \\
\text { edly. Then the mounter dismounts. The duration of the } \\
\text { mount is about } 3-5 \mathrm{~s} \text {. This may be a simple friendly gesture } \\
\text { or a post-conflict behavior. }\end{array}$ & Picture 18 \\
\hline 23 & Show penis & $\begin{array}{l}\text { This is a ritualized behavior shown by juvenile males toward } \\
\text { adult males. Usually, the lower-ranking male approaches the } \\
\text { higher-ranking male, raises one leg, and displays his penis. } \\
\text { The higher-ranking male puts his head on the belly of the } \\
\text { lower-ranking male and licks or touches the penis with his } \\
\text { hand. The juvenile may show his penis from a reclining } \\
\text { position. }\end{array}$ & Picture 19 \\
\hline 24 & Suck penis & $\begin{array}{l}\text { A young male approaches an adult male and jumps on his } \\
\text { head. The adult male holds the younger male by the waist in } \\
\text { such a way that his mouth can reach the young male's penis. } \\
\text { The adult sucks the young male's penis and then the youn- } \\
\text { ger male leaves. }\end{array}$ & Picture 20 \\
\hline
\end{tabular}




\begin{tabular}{|c|c|c|c|}
\hline No. & Repertoire & Definition & Picture \\
\hline 25 & Hold infant & $\begin{array}{l}\text { An adult male holds an infant and may carry it ventrally. } \\
\text { Usually the infant is male. This apparently serves to invite } \\
\text { other adult males to engage in social interaction with the } \\
\text { adult male. }\end{array}$ & Picture 21 \\
\hline 26 & Bridge & $\begin{array}{l}\text { Bridging involves three individuals, an infant or young } \\
\text { juvenile and (a) two adult males, (b) one adult male and one } \\
\text { subadult male, or (c) two adult females. The two older } \\
\text { individuals hold the infant on its back, lower their heads, } \\
\text { and lick the belly and/or genitals of the infant. They will } \\
\text { often teeth-chatter and vocalize excitedly. The infant is } \\
\text { usually male and his penis becomes erect immediately. } \\
\text { Other infants, particularly females, will approach a bridging } \\
\text { triad with excitement as if they wish to participate. }\end{array}$ & Picture 22 \\
\hline 27 & $\begin{array}{l}\text { Genital } \\
\text { inspection }\end{array}$ & $\begin{array}{l}\text { One individual will touch the genitals- the vagina of a } \\
\text { female or the anus of a male-and sniff it or lick it directly. } \\
\text { When a male inspects a female in estrus, it is called a sexual } \\
\text { inspection. }\end{array}$ & Picture 23 \\
\hline 28 & $\begin{array}{l}\text { Sexual } \\
\text { inspection }\end{array}$ & A genital inspection by an adult male of an estrus female. & Picture 24 \\
\hline 29 & Sexual chase & $\begin{array}{l}\text { An adult male chases a female and attempts to mate with } \\
\text { her. The sexual chase differs from the aggressive chase in } \\
\text { that it is slower and is interrupted by pauses. In addition, } \\
\text { although the female attempts to avoid the male, she is less } \\
\text { likely to scream. }\end{array}$ & Picture 25 \\
\hline 30 & $\begin{array}{l}\text { Sexual } \\
\text { grimace }\end{array}$ & $\begin{array}{l}\text { An individual directs a grimace toward an adult of the } \\
\text { opposite sex that may be either nearby or far away. The male } \\
\text { sways his body in a manner that makes him more noticeable } \\
\text { to the female. The grimace differs from a fear grimace in that } \\
\text { the corners of the mouth are not drawn back as far. This is a } \\
\text { sexual solicitation. }\end{array}$ & Picture 26 \\
\hline 31 & Mating & $\begin{array}{l}\text { Three types of mating are described: (1) intromission and } \\
\text { thrusting only; (2) intromission, thrusting, and pausing; and } \\
\text { (3) intromission, thrusting, pausing, and calling. }\end{array}$ & Picture 27 \\
\hline 32 & Harassment & $\begin{array}{l}\text { Individuals approach a mating pair excitedly, touch the } \\
\text { heads, lick, or stick their faces in the faces of the mating } \\
\text { partners. They may also grimace or scream. This does not } \\
\text { generally interrupt the copulation of the mating partners. }\end{array}$ & Picture 28 \\
\hline 33 & Consortship & $\begin{array}{l}\text { An adult male and female form a temporary close affiliative } \\
\text { and sexual relationship during the mating season. They will } \\
\text { move, feed, mate, and groom together, but do not neces- } \\
\text { sarily mate exclusively with one another. Their frequencies } \\
\text { of following one another are much higher than during } \\
\text { non-mating periods. }\end{array}$ & Picture 29 \\
\hline
\end{tabular}




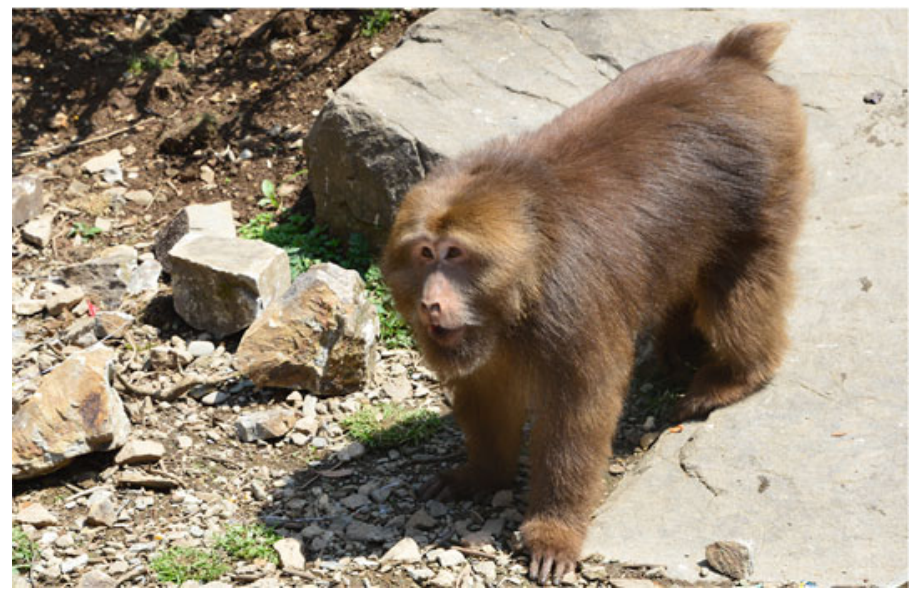

Picture 1 An individual stares another animal

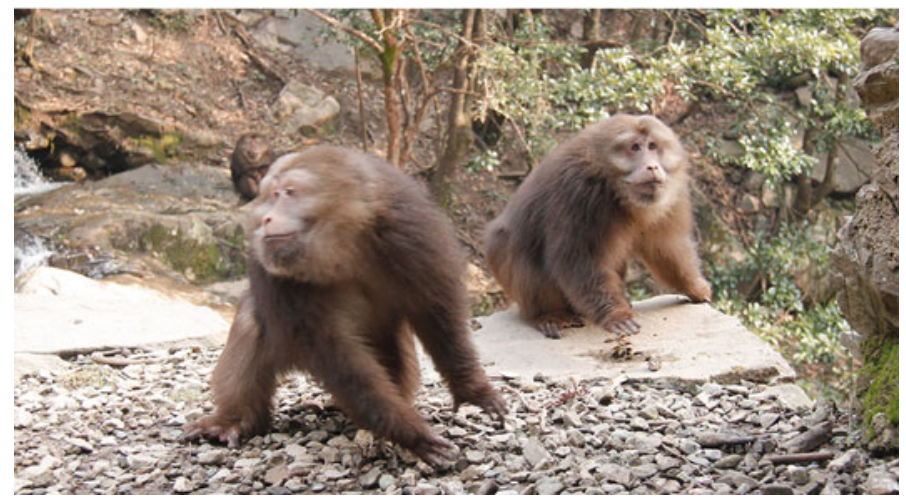

Picture 2 The right adult male slaps toward his front individual

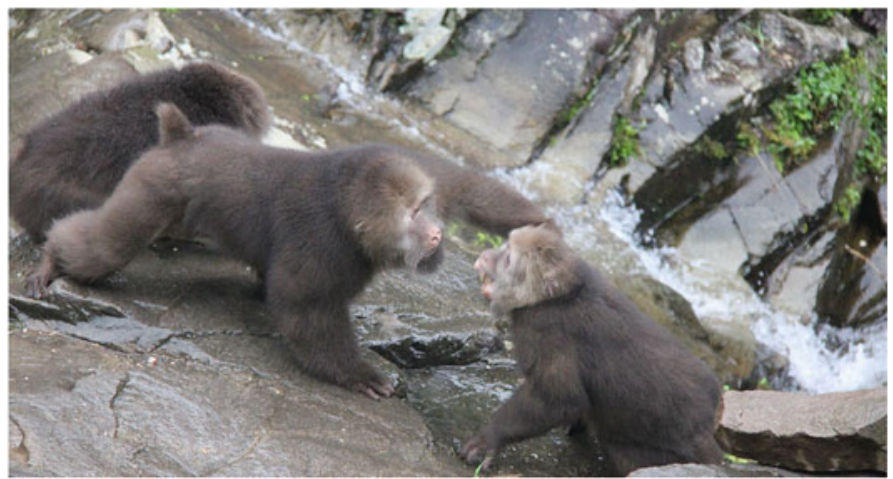

Picture 3 An adult male (middle) seizes another adult male (right) 


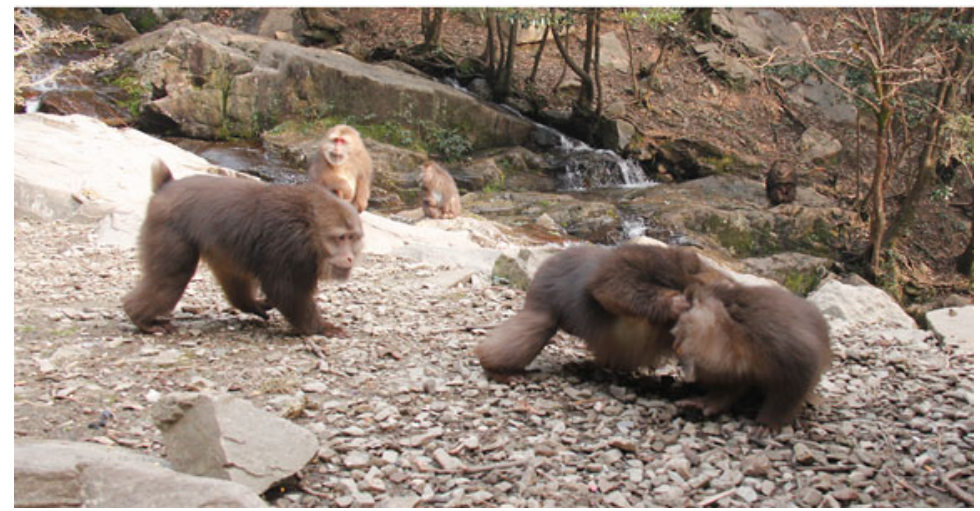

Picture 4 An adult male bites another adult male (two monkeys in right)

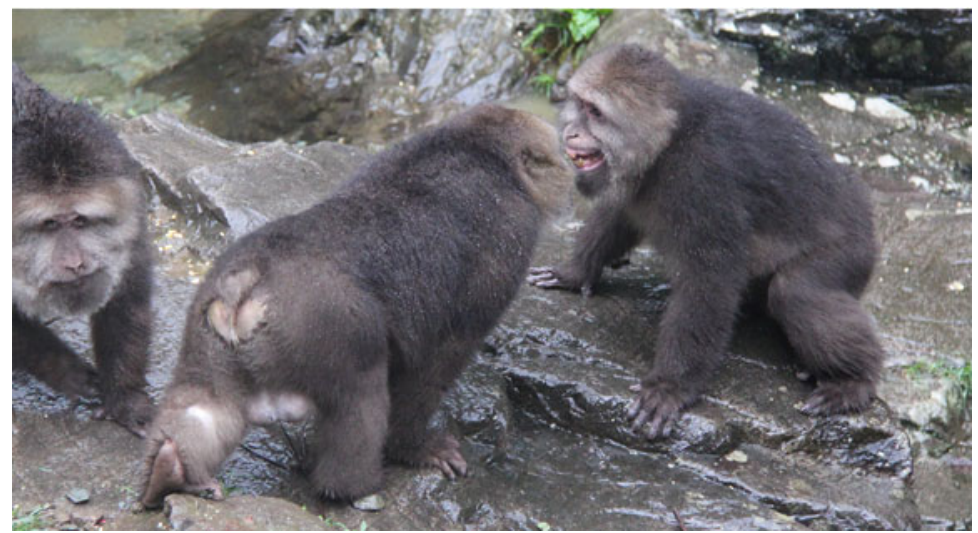

Picture 5 An adult male (right) avoids adult male's (middle) aggression

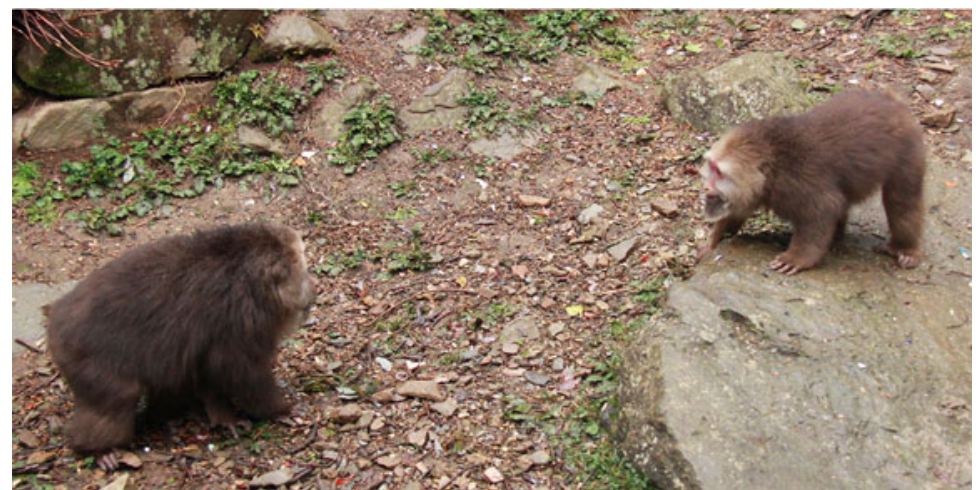

Picture 6 An adult female (right) screams when she is attacked by adult male (left) 


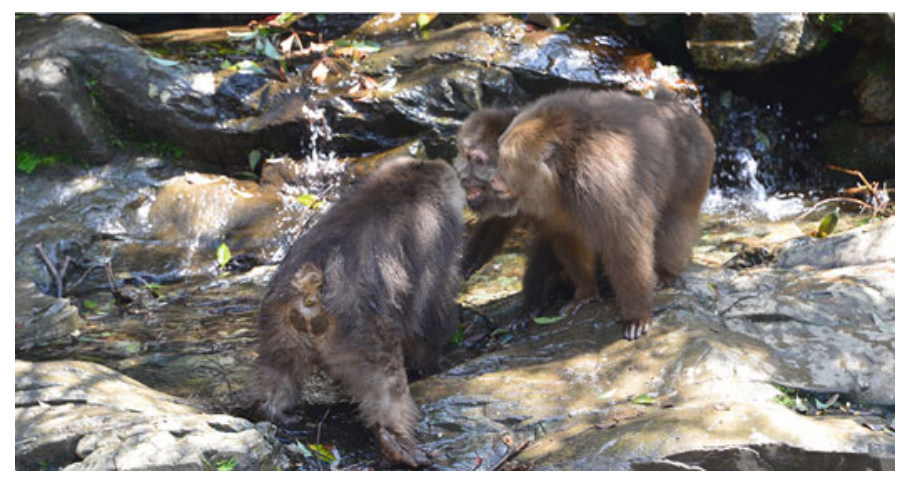

Picture 7 The middle adult male redirects aggression from right adult male to the left adult male

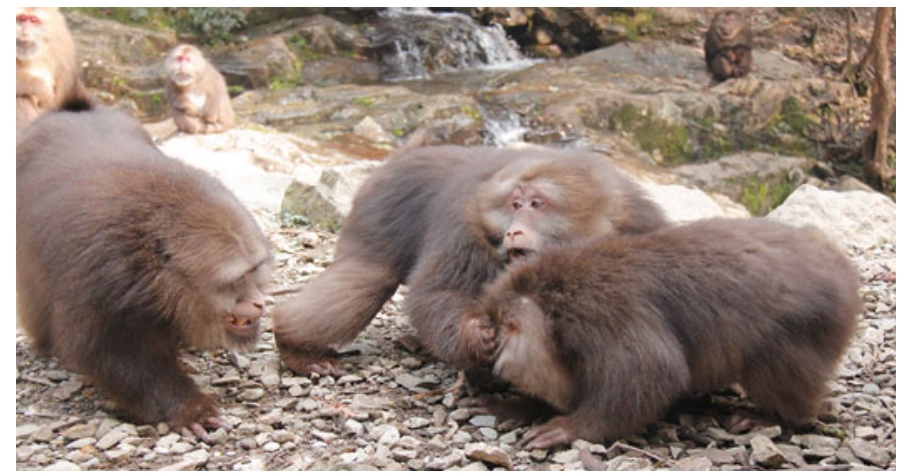

Picture 8 The middle adult male is getting the left male's support when he is in conflict with the right adult male

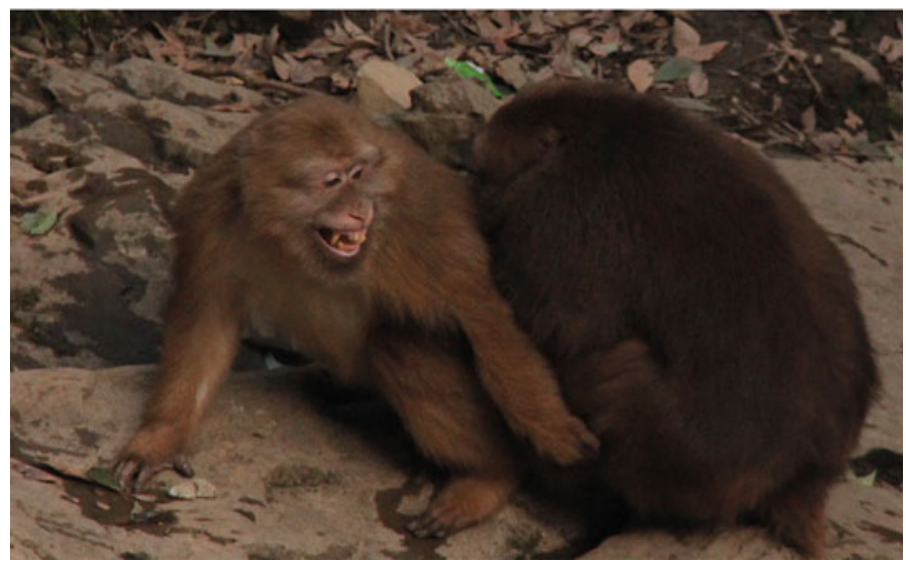

Picture 9 An adult male holds the button of a juvenile male (left) 


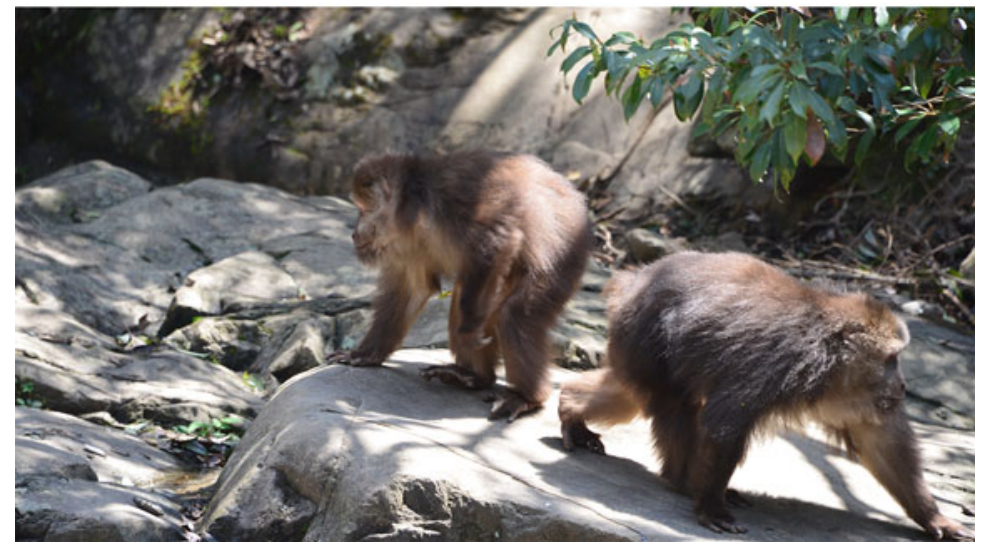

Picture 10 The right adult male is leaving left adult male

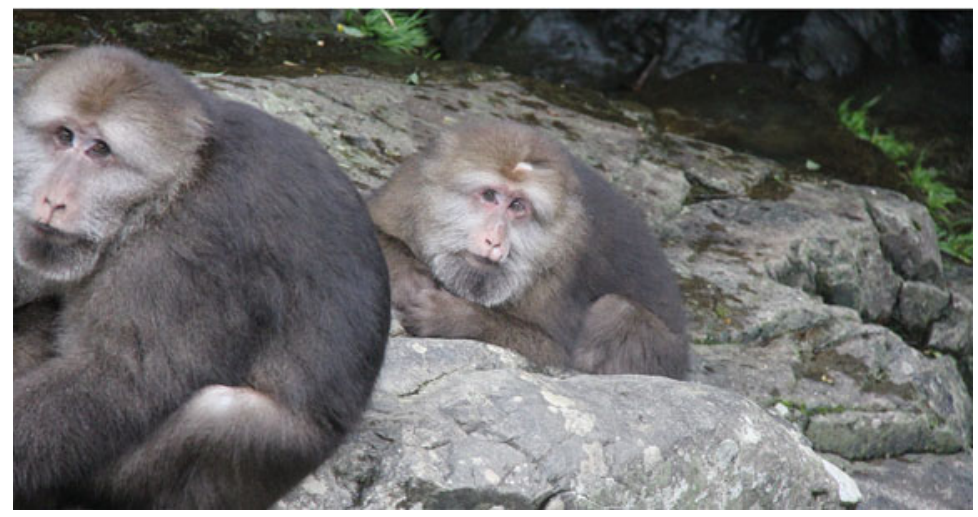

Picture 11 An adult male (left) is in proximity with an adult female within $1 \mathrm{~m}$

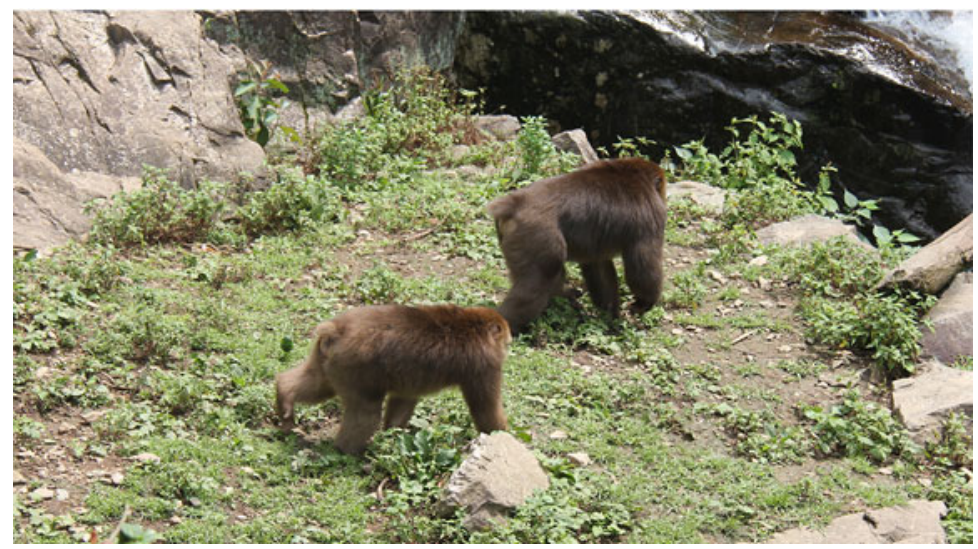

Picture 12 An adult female (left) is following an adult male 


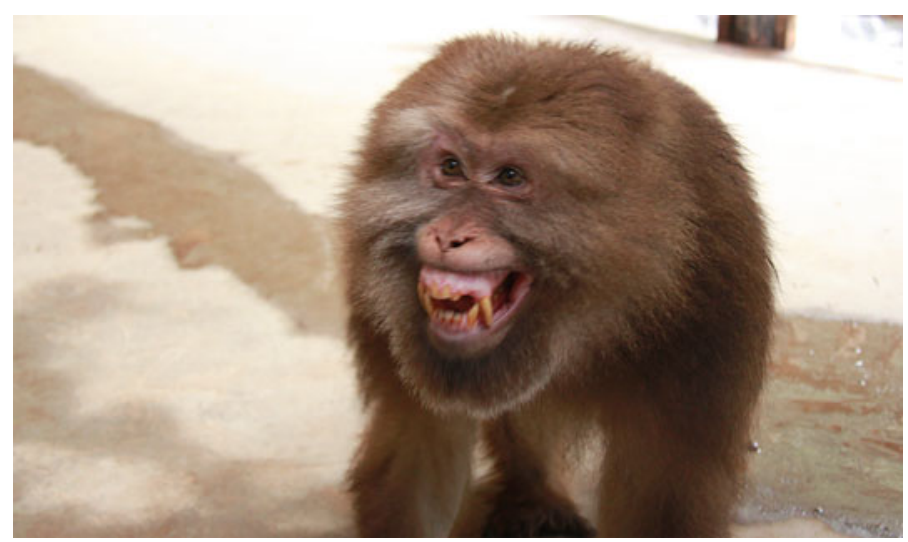

Picture 13 Teeth chatting

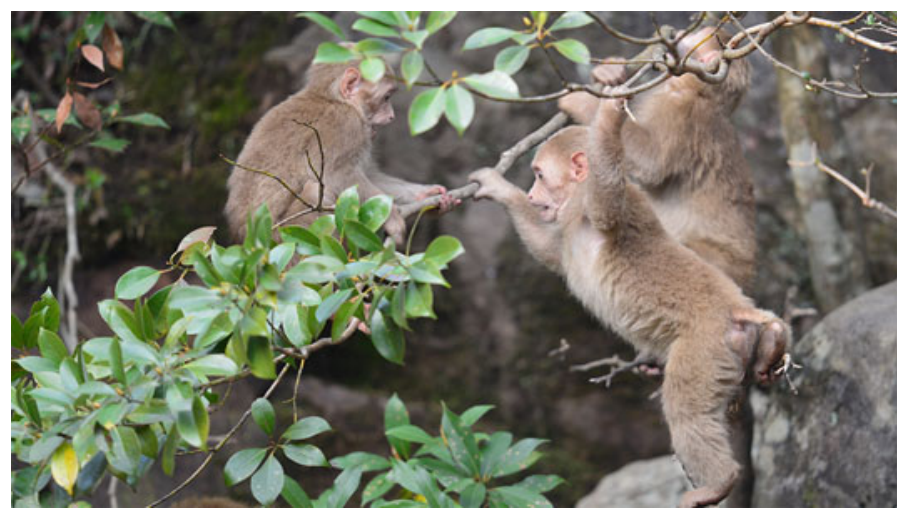

Picture 14 Three juveniles play together

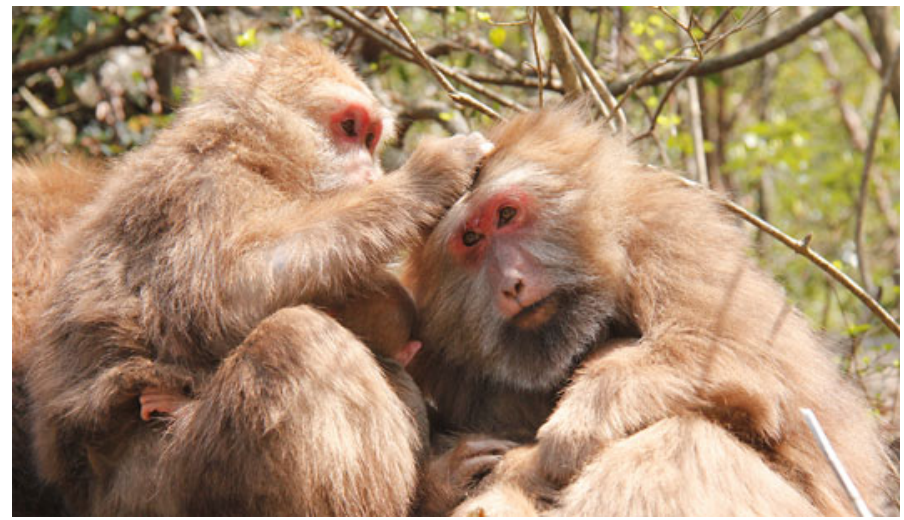

Picture 15 Social grooming between two females 


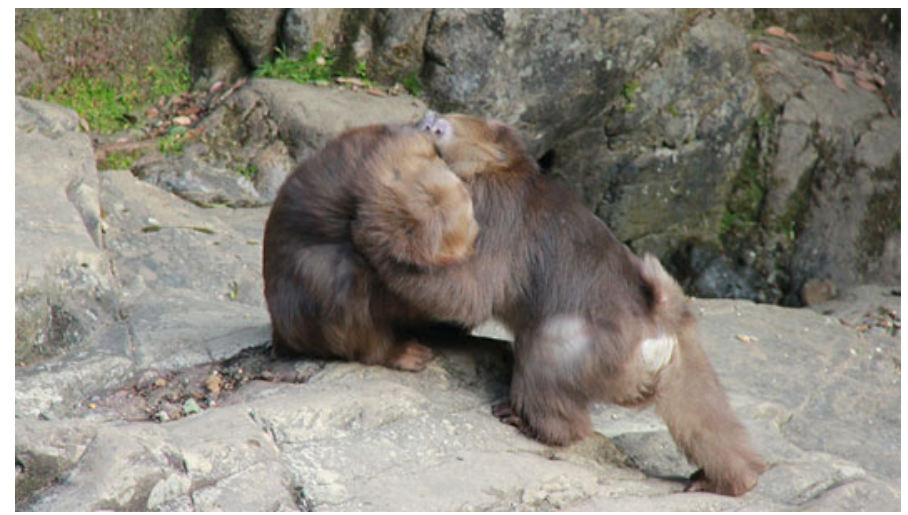

Picture 16 Embrace

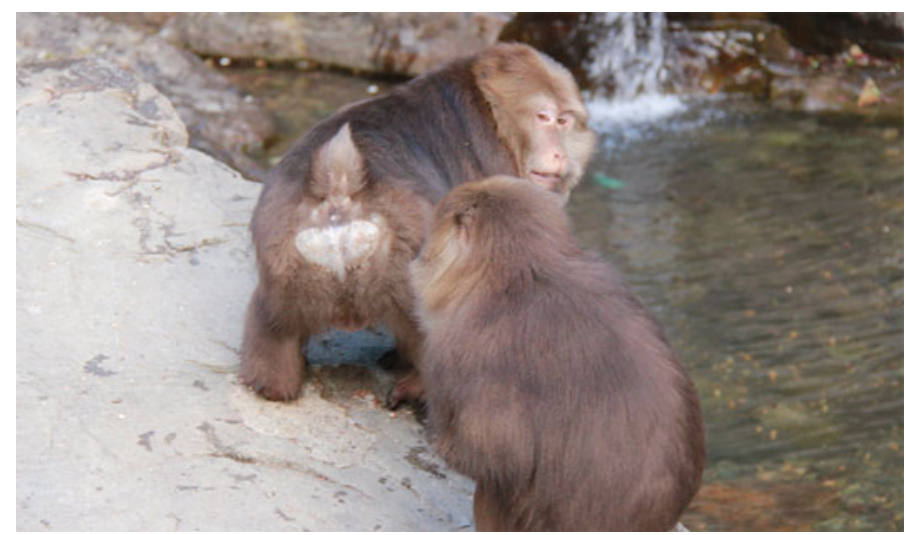

Picture 17 An adult male presents to another male

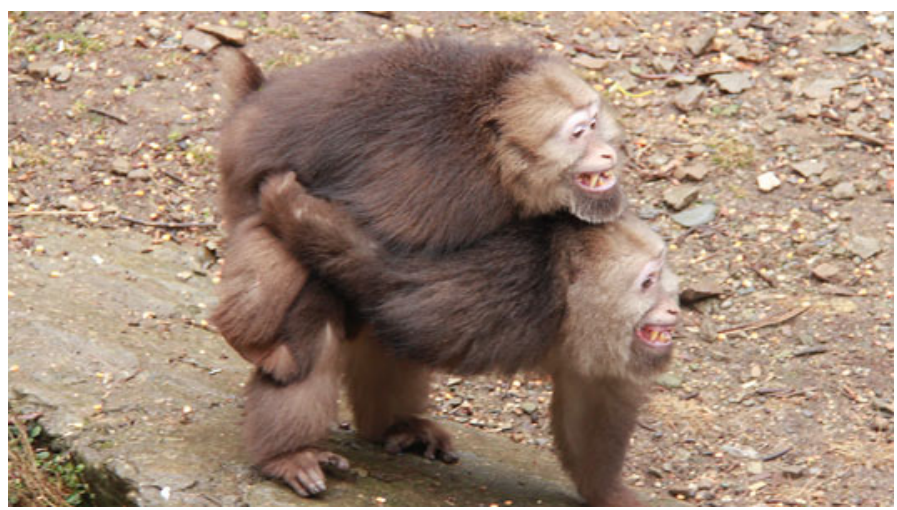

Picture 18 Male-male mount 


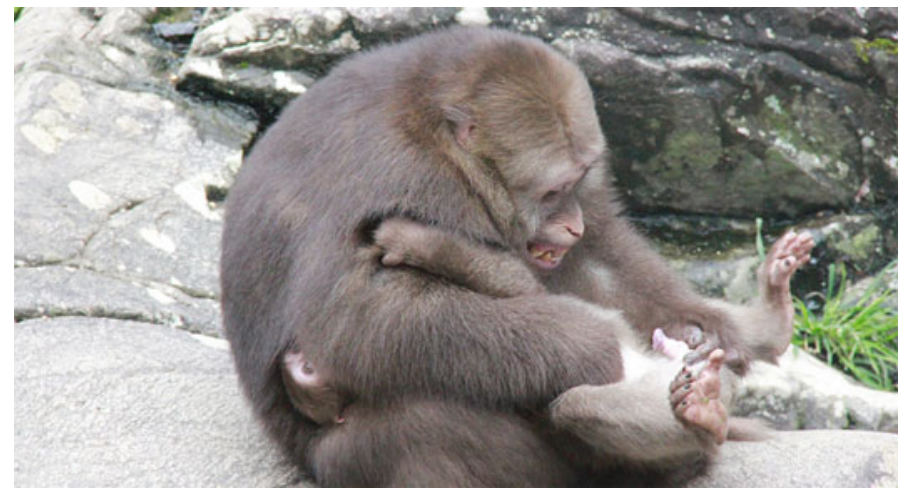

Picture 19 Show the penis

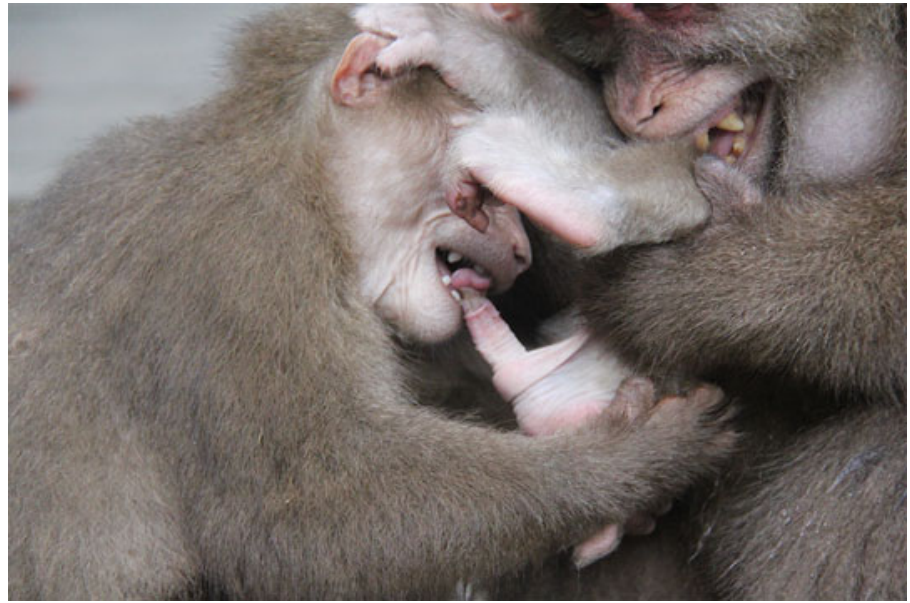

Picture 20 A juvenile (left) is sucking an infant's penis

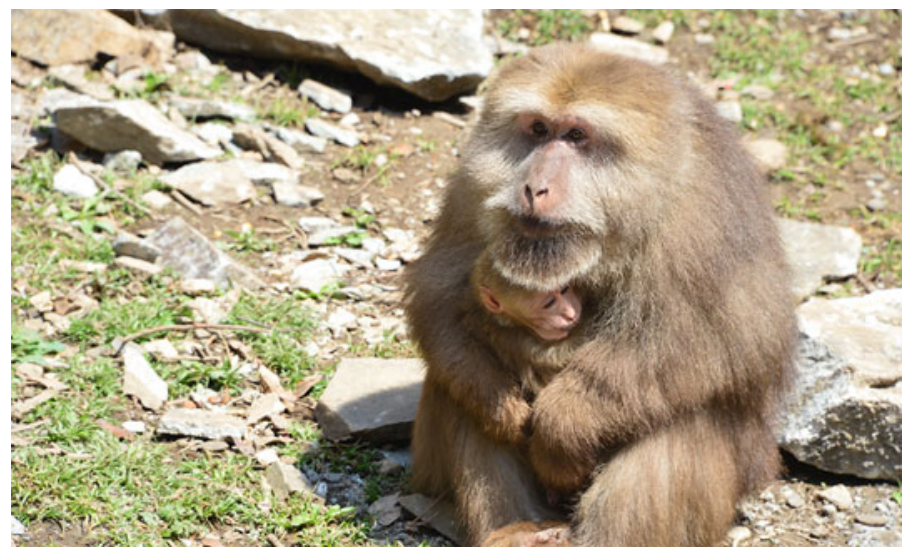

Picture 21 An adult male holds an infant 


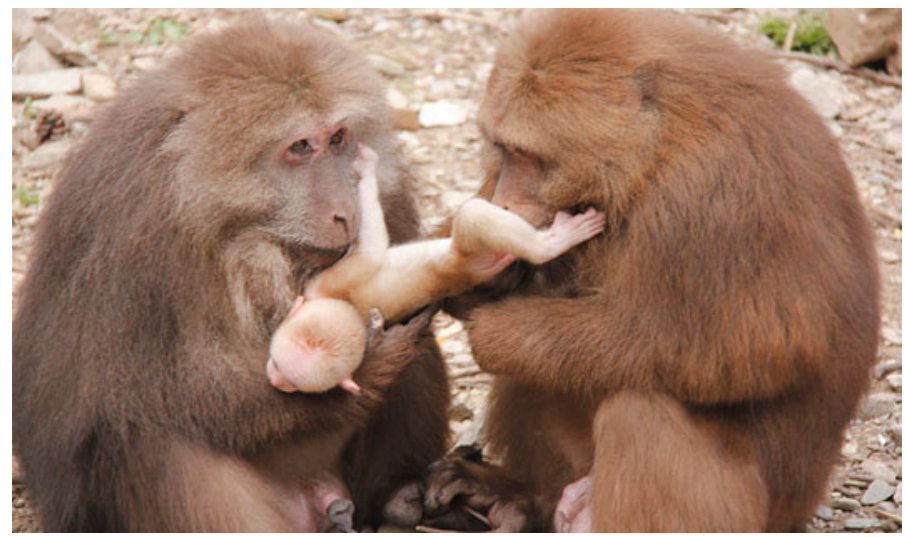

Picture 22 Male-male bridging

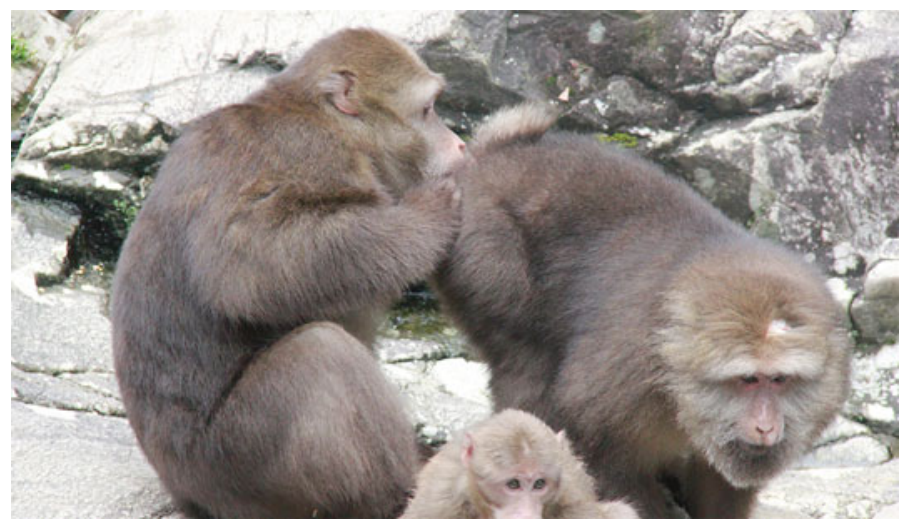

Picture 23 Genital inspection

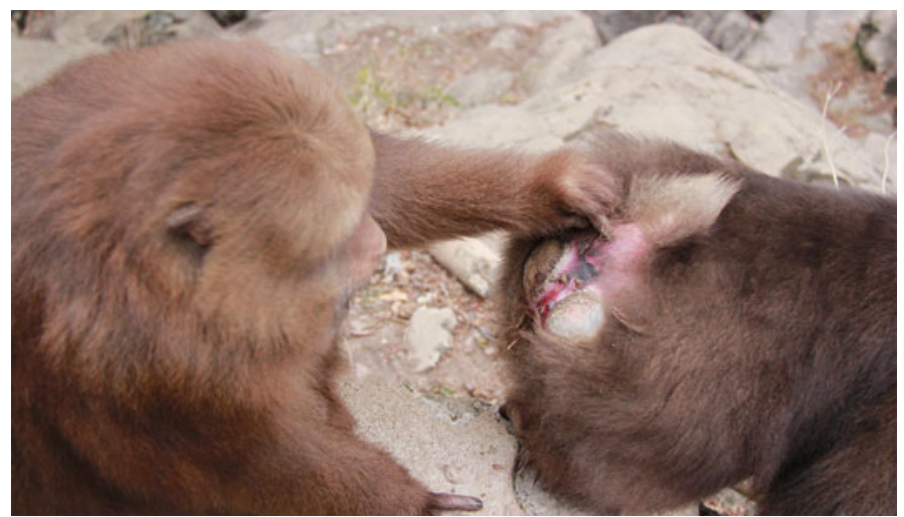

Picture 24 Sexual inspection 


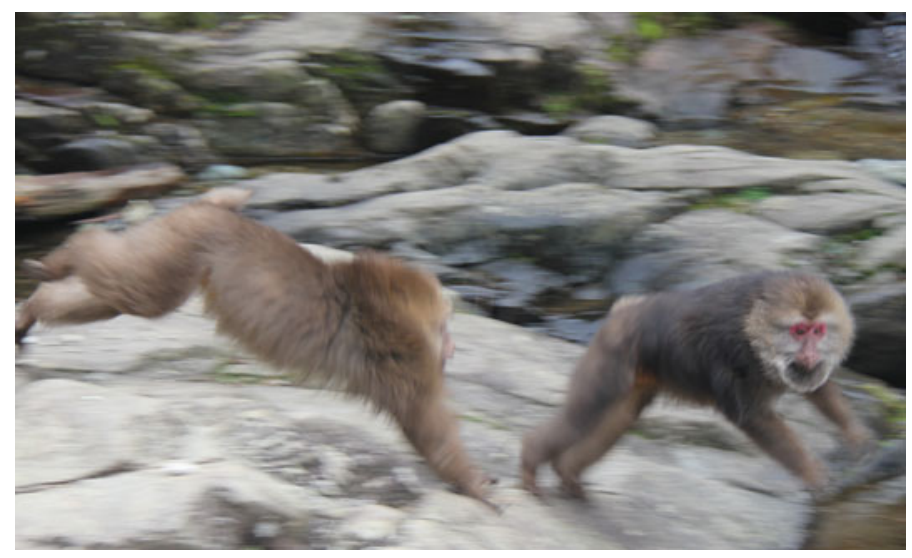

Picture 25 An adult male (left) chases an adult female (right) for mating

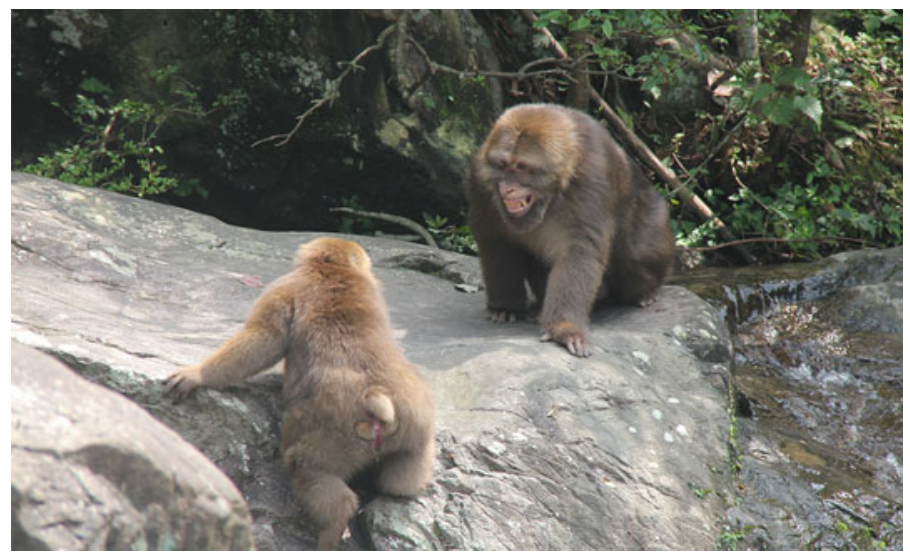

Picture 26 An adult male (right) grimace to an adult female (left)

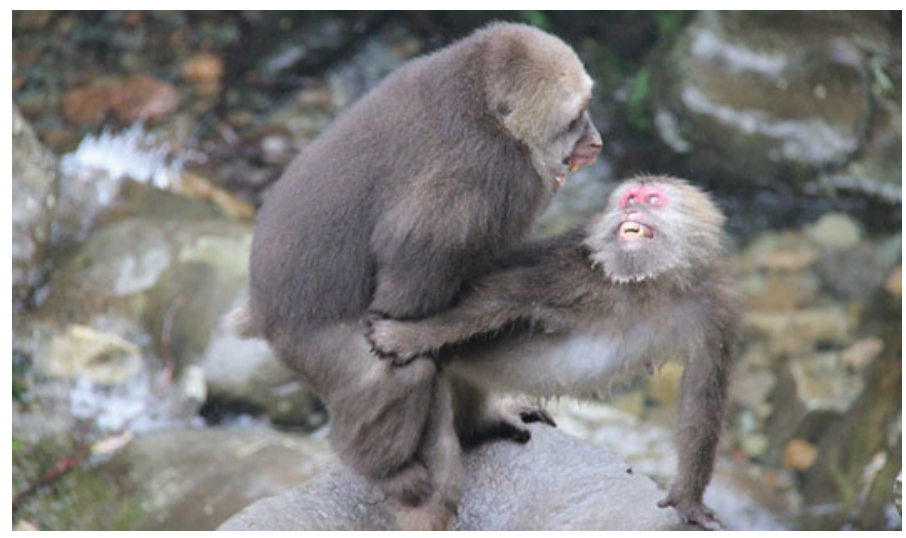

Picture 27 An adult male (left) is mating with an adult female (right) 


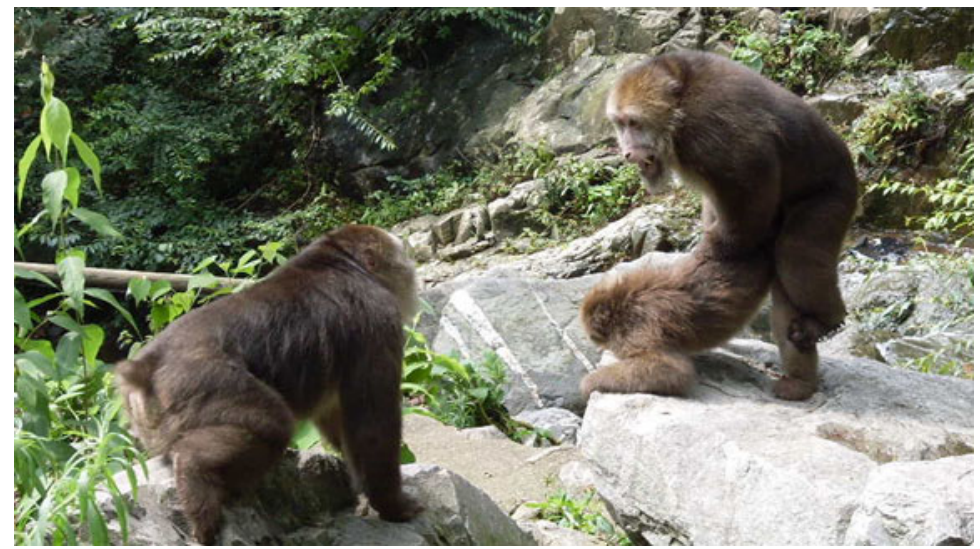

Picture 28 An adult male (left) is harassing a mating pair

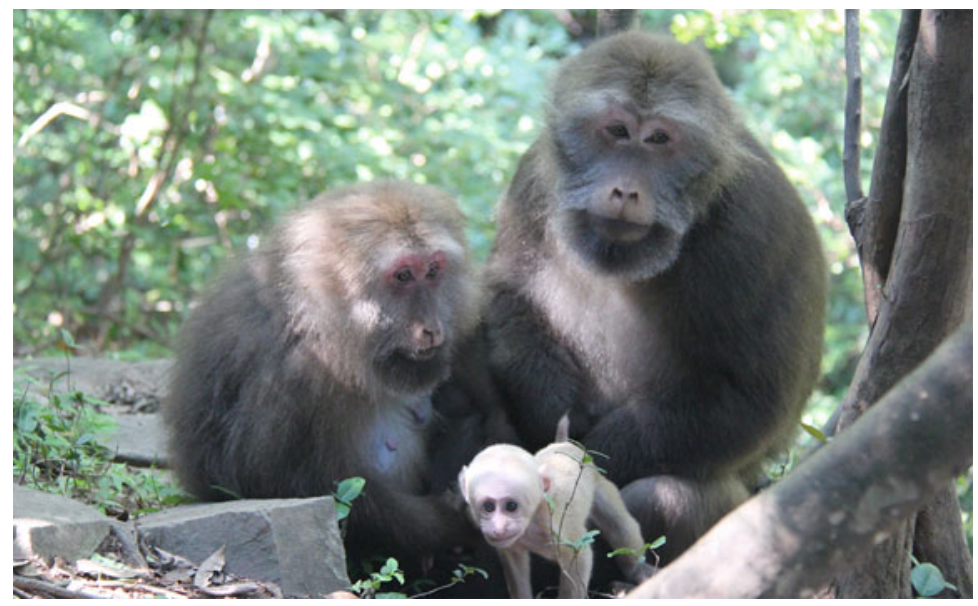

Picture 29 An adult male (right) forms consortship with an adult female (left)

\section{References}

Altmann J (1974) Observational study of behavior: sampling methods. Behaviour 49:227-266

Berman C, Li JH (2002) Impact of translocation, provisioning and range restriction on a group of Macaca thibetana. Int J Primatol 23:283-397

Berman C, Ionica C, Li JH (2004) Dominance style among Macaca thibetana on Mt. Huangshan, China. Int J Primatol 25:1283-1312

Berman C, Ionica C, Dorner M, Li JH (2006) Postconflict affiliation between former opponents in Macaca thibetana on Mt. Huangshan, China. Int J Primatol 27:827-854

Deag J, Crook J (1971) Social behaviour and "agonistic buffering" in the wild Barbary macaque Macaca sylvana L. Folia Primatol 15:183-200

Delson E (1980) Fossil macaques, phyletic relationships and a scenario of development. In: Lindburg D (ed) The macaques: studies in ecology, behavior, and evolution. Van Nostrand Reinhold, New York, pp 31-51 
Fairbanks L (1990) Reciprocal benefits of allomothering for female vervet monkeys. Anim Behav 9:425-441

Fooden J (1980) Classification and distribution of living macaques. In: Lindburg D (ed) The macaques: studies in ecology, behavior, and evolution. Van Nostrand Reinhold, New York, pp 1-9

Fooden J (1983) Taxonomy and evolution of the sinica group of macaques: 4. species account of Macaca thibetana. Fieldiana Zool 17:1-20

Hoelzer G, Hoelzer M, Melnick D (1992) The evolutionary history of the sinica group of macaque monkeys as revealed by mtDNA restriction site analysis. Mol Phylogenet Evol 1:215-222

Jiang XL, Wang YX, Wang QS (1996) Taxonomy and distribution of Tibetan macaque (Macaca thibetana). Zool Res 17:361-369

Kappeler P, Watts D (2012) Long-term field studies of primates. Springer, New York

Li JH (1999) The Tibetan macaque society: a field study. Anhui University Press, Hefei. (In Chinese)

Li JH, Wang QS (1994) Sleeping site of Tibetan macaques in summer. Chin J Zool 29(5): 58

Li JH, Wang QS (1996) Dominance hierarchy and its chronic change in adult male Tibetan macaques (Macaca thibetana). Acta Zool Sin 42:330-334

Li JH, Wang QS, Li M (1994) Studies on population ecology of Tibetan monkeys (Macaca thibetana). II. Reproductive pattern of Tibetan monkeys. Acta Therlol Sin 14(4):255-259

Li JH, Wang QS, Han DM (1996) Fission in a free-ranging Tibetan macaque group at Huangshan Mountain, China. Chin Sci Bull 41:1377-1381

Li JH, Yin HB, Wang QS (2005) Seasonality of reproduction and sexual activity in female Tibetan macaques (Macaca thibetana) at Huangshan, China. Acta Zool Sin 51:365-375

Li JH, Yin HB, Zhou LZ (2007) Non-reproductive copulation behavior among Tibetan macaques (Macaca thibetana) at Huangshan, China. Primates 48:64-72

Li DM, Fan LG, Ran JH, Yin HL, Wang HX, Wu SB, Yue BS (2008) Genetic diversity analysis of Macaca thibetana based on mitochondrial DNA control region sequences. DNA Seq 19 (5):446-452

Liu Y, Li JH, Zhao JY (2006) Sequence variation of mitochondrial DNA control region and population genetic diversity of Tibetan macaques Macaca thibetana in the Huangshan Mountain. Acta Zool Sin 52(4):724-730

Macintosh A, Huffman M, Nishiwaki K, Miyabe-Nishiwaki T (2012) Urological screening of a wild group of Japanese macaques (Macaca fuscata yakui): investigating trends in nutrition and health. Int J Primatol 33(2):460-478

Matheson M, Sheeran L, Li JH, Wagner R (2006) Tourist impact on Tibetan macaques. Anthrozoös 19:158-168

Matsumura S (1999) The evolution of "egalitarian" and "despotic" social systems among macaques. Primates 40:23-31

Ogawa H (1995a) Bridging behavior and other affiliative interactions among male Tibetan macaques (Macaca thibetana). Int J Primatol 16:707-729

Ogawa H (1995b) Recognition of social relationships in bridging behavior among Tibetan macaques (Macaca thibetana). Am J Primatol 35:305-310

Ogawa H (2019) Bridging behavior and male-infant interactions in Macaca thibetana and M. assamensis: insight into the evolution of social behavior in the sinica species-group of macaques. In: Li J-H, Sun L, Kappeler P (eds) The behavioral ecology of the Tibetan Macaque. Springer, Heidelberg

Pan RL, Jablonski N, Oxnard C, Freedman L (1998) Morphometric analysis of Macaca arctoides and M. thibetana in relation to Other Macaque species. Primates 39(4):519-537

Simons N, Lorenz J, Sheeran L, Li JH, Xia DP, Wagner R (2012) Noninvasive saliva collection for DNA analysis from free-ranging Tibetan macaques (Macaca thibetana). Am J Primatol 74:1064-1070

Smuts BB (1985) Sex and friendship in baboons. Aldine, Hawthorne, NY

Smuts B, Cheney D, Seyfarth R, Wrangham R, Struhsaker T (1987) Primate society. University of Chicago Press, Chicago, IL

Spielman D, Brook B, Frankham R (2004) Most species are not driven to extinction before genetic factors impact them. Proc Natl Acad Sci U S A 101:15261-15264

Stanford C (1992) The costs and benefits of allomothering in wild capped langurs (Presbytis pileata). Behav Ecol Sociobiol 30:29-34 
Sun BH, Li JH, Zhu Y, Xia DP (2010) Mitochondrial DNA variation in Tibetan macaque (Macaca thibetana). Folia Zool 59:301-307

Sun L, Xia D-P, Li J-H (2019) Size matters in primate societies: how social mobility relates to social stability in Tibetan and Japanese macaques. In: Li J-H, Sun L, Kappeler P (eds) The behavioral ecology of the Tibetan macaque. Springer, Heidelberg

Thierry B (2000) Covariation of conflict management patterns in macaque societies. In: Aureli F, de Waal FBM (eds) Natural conflict resolution. University of California Press, Berkeley, CA, pp $106-128$

Wada K, Xiong CP (1996) Population changes of Tibetan monkeys with special regard to birth interval. In: Shotake T, Wada K (eds) Variations in the Asian macaques. Tokai University Press, Tokyo, pp 133-145

Wada K, Xiong CP, Wang QS (1987) On the distribution of Tibetan and rhesus monkeys in southern Anhui Province, China. Acta Theiol Sin 7:148-176

Wang GL, Yin HB, Yu G, Wu M (2007) Time budget of adult Tibetan macaques in a day in spring. Chin J Wildlife 29:6-10

Waters S, Harrad A, Chetuan M, Amhaouch Z (2015) Barbary macaque group size and composition in Bouhachem forest, north Morocco. Afr Primates 10:53-56

Xia DP, Li JH, Garber P, Matheson M, Sun BH, Zhu Y (2013) Grooming reciprocity in male Tibetan macaques. Am J Primatol 75:1009-1020

Xiong CP (1984) Studies on the ecology of Tibetan monkeys. Acta Theriol Sin 4:1-9

Xiong CP, Wang QS (1988) Seasonal habitat used by Tibetan monkeys. Acta Theriol Sin 8:176-183

Xiong CP, Wang QS (1991) A comparative study on the male sexual behavior in Thibetan and Japanese monkeys. Acta Theriol Sin 11:13-22

Zhang M, Li JH, Zhu Y, Wang X, Wang S (2010) Male mate choice in Tibetan macaques Macaca thibetana at Mt. Huangshan, China. Curr Zool 56:213-221

Zhang D, Xia DP, Wang X, Zhang QX, Sun BH, Li JH (2018) Bridging may help young female Tibetan macaques Macaca thibetana learn to be a mother. Sci Rep 8:16102

Zhao QK (1993) Sexual behavior of Tibetan macaques at Mt. Emei, China. Primates 34(4):431-444

Zhao QK (1996) Male-infant-male interactions in Tibetan macaques. Primates 37(2):135-143

Zhao JY, Li JH, Liu Y, Yin HB (2005) Research on DNA extraction from old feces of Macaca thibetana. Acta Theriol Sin 25:410-413

Zhu Y, Li JH, Xia DP, Chen R, Sun BH (2008) Inbreeding avoidance by female Tibetan macaques Macaca thibetana at Huangshan, China. Acta Zool Sin 54:183-190

Open Access This chapter is licensed under the terms of the Creative Commons Attribution 4.0 International License (http://creativecommons.org/licenses/by/4.0/), which permits use, sharing, adaptation, distribution and reproduction in any medium or format, as long as you give appropriate credit to the original author(s) and the source, provide a link to the Creative Commons licence and indicate if changes were made.

The images or other third party material in this chapter are included in the chapter's Creative Commons licence, unless indicated otherwise in a credit line to the material. If material is not included in the chapter's Creative Commons licence and your intended use is not permitted by statutory regulation or exceeds the permitted use, you will need to obtain permission directly from the copyright holder.

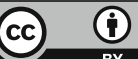

